OPEN ACCESS

Edited by:

Cristina Maccalli,

Sidra Medicine, Qatar

Reviewed by:

Alessandro Poggi,

San Martino Hospital (IRCCS), Italy

Tessa Kerre,

Ghent University, Belgium

${ }^{*}$ Correspondence:

Fatemeh Rahbarizadeh

rahbarif@modares.ac.ir

${ }^{\dagger}$ These authors share first authorship

Specialty section: This article was submitted to

Cancer Immunity and Immunotherapy,

a section of the journal

Frontiers in Immunology

Received: 26 August 2021 Accepted: 07 October 2021 Published: 28 October 2021

Citation: Safarzadeh Kozani P,

Safarzadeh Kozani $P$ and Rahbarizadeh F (2021)

Optimizing the Clinical Impact of CAR-T Cell Therapy in B-Cell Acute Lymphoblastic Leukemia: Looking Back While Moving Forward.

Front. Immunol. 12:765097. doi: 10.3389/fimmu.2021.765097

\section{Optimizing the Clinical Impact of CAR-T Cell Therapy in B-Cell Acute Lymphoblastic Leukemia: Looking Back While Moving Forward}

\author{
Pouya Safarzadeh Kozani ${ }^{1,2+}$, Pooria Safarzadeh Kozani ${ }^{3 \dagger}$ and Fatemeh Rahbarizadeh ${ }^{3,4 *}$ \\ 1 Department of Medical Biotechnology, Faculty of Paramedicine, Guilan University of Medical Sciences, Rasht, Iran, \\ 2 Student Research Committee, Medical Biotechnology Research Center, School of Nursing, Midwifery, and Paramedicine, \\ Guilan University of Medical Sciences, Rasht, Iran, ${ }^{3}$ Department of Medical Biotechnology, Faculty of Medical Sciences, \\ Tarbiat Modares University, Tehran, Iran, ${ }^{4}$ Research and Development Center of Biotechnology, Tarbiat Modares University, \\ Tehran, Iran
}

Chimeric antigen receptor T-cell (CAR-T) therapy has been successful in creating extraordinary clinical outcomes in the treatment of hematologic malignancies including relapsed or refractory $(R / R) B$-cell acute lymphoblastic leukemia (B-ALL). With several FDA approvals, CAR-T therapy is recognized as an alternative treatment option for particular patients with certain conditions of B-ALL, diffuse large B-cell lymphoma, mantle cell lymphoma, follicular lymphoma, or multiple myeloma. However, CAR-T therapy for B-ALL can be surrounded by challenges such as various adverse events including the lifethreatening cytokine release syndrome (CRS) and neurotoxicity, B-cell aplasia-associated hypogammaglobulinemia and agammaglobulinemia, and the alloreactivity of allogeneic CAR-Ts. Furthermore, recent advances such as improvements in media design, the reduction of ex vivo culturing duration, and other phenotype-determining factors can still create room for a more effective CAR-T therapy in R/R B-ALL. Herein, we review preclinical and clinical strategies with a focus on novel studies aiming to address the mentioned hurdles and stepping further towards a milestone in CAR-T therapy of B-ALL.

Keywords: chimeric antigen receptor, cytokine release syndrome, neurotoxicity, acute lymphoblastic leukemia, adoptive cell therapy, cancer immunotherapy

\section{INTRODUCTION}

B-cell acute lymphoblastic leukemia (B-ALL) is characterized by the presence of poorly differentiated abnormal B-cell progenitor cells that have a rapid rate of proliferation in the bone marrow (1). B-ALL is the most prevalent form of acute leukemia in children in the US $(2,3)$. With around 3000 newly diagnosed cases of children with B-ALL each year, overall survival (OS) surpasses $85 \%$ in children (2-4). However, in adult B-ALL patients, OS is not as favorable as it is in children with B-ALL and it ranges from $50 \%$ to up to $60 \%(5,6)$. Even though chemotherapy regimens mediate high rates of complete remission (CR), $40 \%$ to $50 \%$ of adult B-ALL patients ultimately experience disease relapse (7-9). Relapsed or refractory (R/R) cases of B-ALL have unfavorable prognosis with CR rates ranging from around 35\% and up to $10 \%$ in the first and 
second recovery from the disease, respectively (7-9). Therefore, researchers have been investigating other types of treatments capable of mediating better clinical outcomes and mitigated levels of side effects and adverse events.

Cancer immunotherapy first started as an idea to employ the patients' immune system and its components as fighting tools against various types of neoplasms $(10,11)$. Today, monoclonal antibody (mAb)-based therapies, cancer vaccines, adoptive cell therapy (ACT), and oncolytic viruses are among famous types of cancer immunotherapy that have gained preclinical and clinical success (10). The clinical success of adoptively transferred T cells genetically engineered to express chimeric antigen receptors (CAR-Ts) has created a new era in the treatment of B-cellbased malignancies (12-17). The theory of utilizing $\mathrm{T}$ cells as fighting tools for a selective fight against cancer, which started in the early 1990s, has now become a treatment option for certain patients with B-cell-based malignancies (12-20). Over the past few years, the field of CAR-T therapy has progressed remarkably $(11,21)$. In particular, various CAR generations have been developed and many innovative strategies have been proposed, aimed at improving the safety and efficacy of CAR-T therapy (11, 20-23).

CD19-redirected CAR-T therapy of children and adults with $\mathrm{R} / \mathrm{R}$ B-ALL results in high remission rates (67\% to 93\%) (12-17). The capacity of CD19-redirected CAR-Ts for in vivo activation, expansion, and robust tumoricidal activity, which results in the mentioned high rates of disease remission even in patients with $\mathrm{R} / \mathrm{R} \mathrm{B}-\mathrm{ALL}$, leads to adverse events and toxicities such as cytokine release syndrome (CRS), neurologic toxicities, and Bcell aplasia $(14,24-27)$. CRS is a systemic inflammatory condition mediated by various cytokines produced by CAR-Ts and other cells of the immune system $(27,28)$. C-reactive protein (CRP), interferon- $\gamma$ (IFN- $\gamma$ ), interleukins (ILs) such as IL-1, IL-2, soluble IL-2 receptor alpha chain (IL-2R $\alpha$ ), IL-4, IL-6, IL-8, and IL-10, granulocyte-macrophage colony-stimulating factor (GM$\mathrm{CSF}$ ), granzyme $\mathrm{B}$, and tumor necrosis factor- $\alpha$ (TNF- $\alpha$ ) are among the most important mediators of CRS $(27,28)$. CRS severity can range from mild levels to high levels necessitating intensive care and urgent medical intervention (27). Moreover, CRS manifests itself as fever, tachycardia, hypotension, hypoxia, etc. (27). Additionally, the pathogenesis of CAR-T-related neurologic toxicities is not very well-known; however, it is evident that this incidence is observed in CRS-developing patients $(25,26)$. Neurologic toxicities can happen following or before CRS onset and it has been evident that its severity correlates with CRS severity $(12,25)$. Both of these adverse events are important incidences and they may limit the successful clinical outcomes of B-ALL CAR-T therapy $(25,26)$. It is also worth mentioning that even though most CAR-Trelated adverse events are managed quite efficiently, there might still be room for improvement.

In addition to CRS and neurologic toxicities, B-cell aplasia is another CAR-T-related toxicity occurring during CAR-T therapy of B-ALL (29). B-cell aplasia is the result of on-target off-tumor toxicity of CD19-redirected CAR-Ts against normal B-cells which occurs simultaneously with the targeting of malignant $\mathrm{CD}_{1} 9^{+}$blasts (29). B-cell aplasia is considered a tool for measuring the persistence of CAR-Ts after obtaining the desired clinical outcomes (14, 24). Scientific evidence has demonstrated that patients with short durations of B-cell aplasia often suffer from disease relapse (24). Furthermore, Bcell aplasia puts the recipients of CD19-redirected CAR-Ts at risk of various types of infectious diseases (29); therefore, clinical interventions are highly required for mitigating the consequences of this unfavorable event.

Moreover, since the generation of autologous CAR-Ts is not always feasible, allogeneic CAR-Ts may be considered as suitable alternatives (30). However, using allogeneic CAR-Ts is also hindered by two limitations $(30,31)$. The first limitation is the incidence of graft-versus-host disease (GvHD) which can be lifethreatening, and the second limitation is that allogeneic CAR-Ts might be rapidly attacked and eradicated by the immune system of the recipients $(30,31)$. Both of these hurdles significantly obstruct the tumoricidal activity of allogeneic CAR-Ts; therefore, counterstrategies are highly required for tackling these caveats $(30,31)$. Herein, we review recent studies that have tried to improve the clinical outcomes of CAR-T therapy in patients with R/R B-ALL by addressing the mentioned limitations. Furthermore, we also discuss preclinical and clinical studies that have investigated other factors such as media design, the duration of ex vivo culturing for CAR-T generation, and various phenotype-determining factors that are important for a more efficacious CAR-T therapy in B-ALL and may help achieve better clinical outcomes.

\section{CAR-T FUNDAMENTALS}

The commercial success story of CAR-Ts started in 2017 when the US Food and Drug Administration (FDA) approved the first CAR-T therapy for medical use (32). To this day, there are five FDA-approved CAR-T products available on the market for five different hematological malignancies (32-38). In particular, tisagenlecleucel has been approved for the treatment of certain subjects with B-ALL or diffuse large B-cell lymphoma (DLBCL) $(32,36)$. Axicabtagene ciloleucel is another CAR-T product which has been approved for DLBCL and follicular lymphoma (FL) (33, 38). In addition, brexucabtagene autoleucel has been approved for certain patients with mantle cell lymphoma (MCL) or B-ALL whereas lisocabtagene maraleucel has been FDA-approved for the treatment of certain individuals with DLBCL $(37,39)$. Recently, Bristol Myers Squibb's idecabtagene vicleucel was FDA-approved for multiple myeloma (MM) (34, 35). Tisagenlecleucel, axicabtagene ciloleucel, brexucabtagene autoleucel, and lisocabtagene maraleucel use CD19 as their target antigen while idecabtagene vicleucel targets B-cell maturation antigen (BCMA) (32-38). It is important to mention that all of these products have been approved for the treatment of certain patients with particular conditions of the mentioned oncological indications (32-38).

CAR-Ts, also known as "living drugs", are T cells that have been genetically manipulated to express CARs on their surface 
(40). These effector cells combine the precise specificity of mAbs with the cytotoxicity of $\mathrm{T}$ lymphocytes, without the need for major histocompatibility complex (MHC); therefore, CAR-Ts are capable of selectively targeting cells proficient in the expression of the desired target antigen while remaining unreactive towards those deficient in target antigen expression (40). CAR-Ts are either redirected towards tumor-associated antigens (TAAs) or tumor-specific antigens (TSAs) of interest expressed on the surface of tumor cells (40). In detail, cell surface-expressed TAAs or TSA are membrane-bound antigens whose expression and surface presentation is independent of MHC molecules (23). Therefore, these antigens can be targeted using mAbs and CAR-Ts (23). On the other hand, intracellular TSAs or TAAs are processed and presented by MHC molecules (41). Targeting such antigens cannot be achieved using CAR-Ts (41). Instead, T cells with engineered T-cell receptors (TCRs) specific for a particular MHC-presented peptide antigen can be beneficial (41).

CARs are synthetic receptors made of an extracellular domain (composed of a targeting domain and a hinge), a transmembrane (TM) domain, and an intracellular domain (composed of a primary $\mathrm{T}$-cell activation domain and one or two costimulatory domains) (40). The targeting domain of CARs is mainly composed of a single-chain variable fragment ( $\mathrm{scFv}$ ) of a $\mathrm{mAb}$ and is responsible for the selective targeting ability of CARs (40). The hinge is responsible for attaching the targeting domain to the TM domain and is mainly derived from CD8, CD28, IgG1, or IgG4 (40). The TM domain, which acts as the bridging fragment between the extracellular domain and the intracellular domain, can be derived from molecules such as $\mathrm{CD} 8 \alpha, \mathrm{CD} 3 \zeta, \mathrm{CD} 28, \mathrm{CD} 4$, and the inducible T-cell co-stimulator (ICOS) (40). Moreover, co-stimulatory domains are considered as the helping hand of the primary $\mathrm{T}$-cell activation domain responsible for CAR-T activation upon target antigen encountering (42-45). In particular, CD28, 4-1BB (CD137), OX40 (CD134), and ICOS have been used as co-stimulatory domains (42-45). It has been demonstrated that co-stimulatory domains possess properties that determine the fate of the engineered effector cells since they can induce memory or effector T-cell phenotype in CAR-Ts $(1,46,47)$. Additionally, the $\mathrm{CD} 3 \zeta$ part of the TCR CD3 complex, FceRI $\gamma, \mathrm{CD} 3 \epsilon, \mathrm{DAP} 10$, DAP12, the $\zeta$-chain of TCR-associated protein kinase $70 \mathrm{kDa}$ (ZAP70), the lymphocyte-specific protein tyrosine kinase (LCK), and fyn are all among the primary activation domains so far used in the construct of CAR-Ts (48-50).

The structural evolution of CAR-Ts can be described based on their different generations. First-generation CAR-Ts had all of the mentioned domains but they did not have any co-stimulatory domain which resulted in their inadequate antitumor activity and persistence (51). As a solution, second- and third-generation CAR-Ts were designed to have one and two co-stimulatory domains, respectively, resulting in their superior antitumor activity and persistence over their predecessors (52, 53). Fourth-generation CAR-Ts are second-generation CAR-Ts that have an inducer domain for the expression of a cytokine of interest, such as IL-2, in their intracellular domain (instead of a secondary co-stimulatory domain) (54). Fourth-generation CAR-Ts are known as " $T$ cells redirected for universal cytokinemediated killing" (TRUCKs) or armored CARs since they deliver a transgenic product to the targeted tumor tissue enhancing the tumoricidal activity and efficacy of CAR-Ts (54). Fifth-generation CAR-Ts are structural counterparts of second-generation CARTs but they harbor an intracellular domain of a cytokine receptor (Figure 1) $(55,56)$. With all the good news surrounding this type of therapy for B-ALL, there are remaining challenges such as CAR-T-associated toxicities including CRS and neurotoxicity,

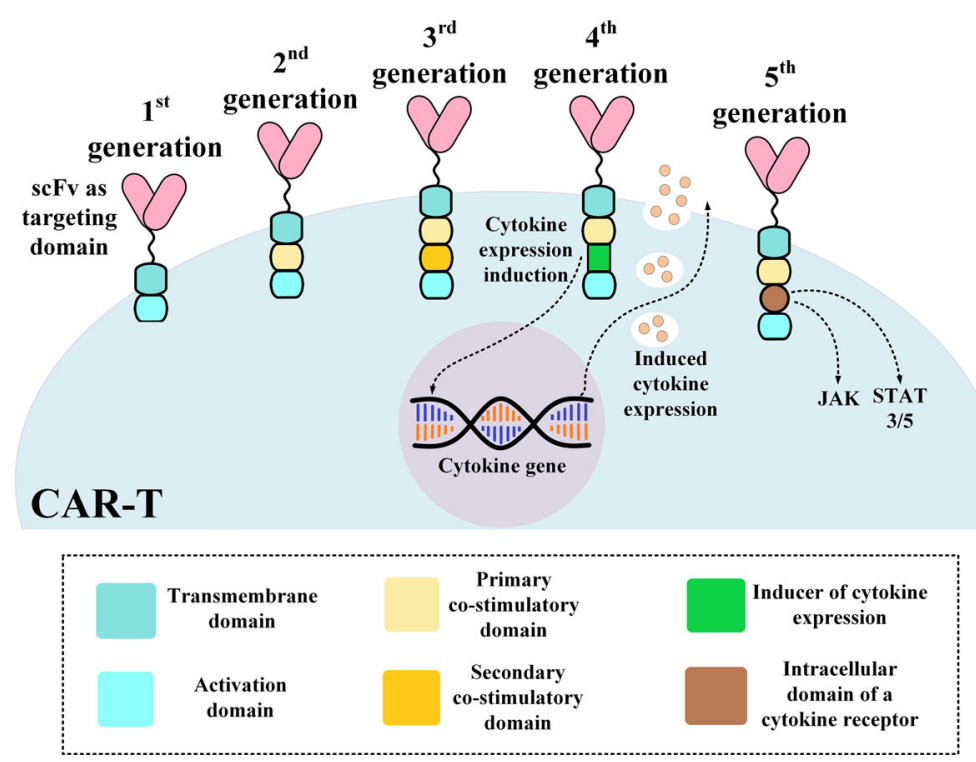

FIGURE 1 | An illustration of different CAR-T generations. CAR, chimeric antigen receptor; scFv, single-chain variable fragment. 
which can be mild to life-threatening, the caveats of using allogeneic CAR-Ts, and other factors whose optimization broadens the success zone of B-ALL CAR-T therapy. In the upcoming sections of this article, we will discuss strategies for addressing these hurdles.

\section{CLINICAL PROCEDURES FOR IMPROVING THE EFFICACY AND SAFETY OF B-ALL CAR-T THERAPY}

\subsection{CRS and Neurotoxicity Mitigation}

CRS is the most important B-ALL CAR-T therapy-associated toxicity resulting from CAR-T-induced rapid immune activation (57-59). CRS can lead to various serious damages including cardiac toxicity, hyponatremia, and other complications (57-59). Of note, CAR-T therapy-related cardiac toxicity or cardiotoxicity is poorly recognized. However, sinus tachycardia, increase level of blood troponin, left ventricular systolic function (LVSD), profound hypotension, and decompensated heart failure (DHF) are among cardiovascular-related adverse events observed during CAR-T therapies (60). Also, hyponatremia is characterized by serum sodium $(\mathrm{Na})$ levels below $135 \mathrm{mEq} / \mathrm{L}$, and is reported to be common among patients receiving CD19redirected CAR-T therapy (58). Moreover, neurotoxicity is another CAR-T-associated adverse event that is not yet fully known but the available data indicate that both activated CARTs and endogenous T lymphocytes, and the cytokines secreted by them, may be responsible for post-CAR-T therapy neurotoxicity (61-63). Furthermore, recent single-cell RNA sequencing data have demonstrated that mural cells, that are responsible for the integrity of the brain-blood barrier (BBB), express the CD19 antigen (64). Researchers have added that the expression of CD19 in the brain emerges early in development and continues throughout adulthood (64). Additionally, these data indicate that mouse mural cells exhibit lower levels of CD19 expression which may be responsible for limitations in preclinical neurotoxicity models (64). So far, several clinical strategies, discussed in the upcoming section, have been developed to either prevent CRS and neurotoxicity or to control them and their damaging effects. Furthermore, designing approaches can also be beneficial in the prevention of CAR-T-associated toxicities (50). For instance, instead of the generally used $\mathrm{CD} 3 \zeta$ activation domain, researchers have designed and generated CAR-Ts with DAP12 as the activation domain (50). In detail, these second-generation CAR-Ts are made of the natural killer group 2D (NKG2D) ectodomain fused to $4-1 \mathrm{BB}$ and the DAP12 cytoplasmic domain (which acts as the activation domain) (50). This design resulted in reduced levels of IFN- $\gamma$, TNF- $\alpha$, and IL- 2 release during tumor cell lysis with lower proliferative activity upon repeated antigen stimulation but similar tumoricidal activity in comparison with that of NKG2D CAR-Ts with the CD3 $\zeta$ activation domain (50). Naturally, NKG2D receptor has the role of a primary activation signal in natural killer (NK) cells whereas it acts as a costimulatory signal in $\mathrm{T}$ lymphocytes (65). In detail, the
NKG2D receptor is a homodimer molecule that interacts with the adaptor molecules DAP10 or DAP12 based on the expressed NKG2D isoform (65). Moreover, mouse and human NK cells, T cells $(\alpha \beta$ and $\gamma \delta)$, and natural killer T (NKT) cells express a longer isoform of NKG2D that interacts with DAP10 (65). In addition, mouse NK cells also express a shorter splice variant of NKG2D that associate with DAP12 (65). Both DAP10 and DAP12 are responsible for triggering downstream cell signaling cascades in association with NKG2D upon ligand encountering (65).

\subsubsection{IL-1 and IL-6 Blockade}

Recently, studies have shown that IL-1 and IL-6 released by monocytes and macrophages are the main reasons for CAR-Tassociated CRS and immune effector cell-associated neurotoxicity syndrome (ICANS) $(66,67)$. In detail, monocytes play a more important role than macrophages in CRS-progressing IL-1 and IL-6 secretion (67). Preclinical data indicate that monocyte ablation or IL-6 receptor blockade using tocilizumab can prevent CRS but not lethal neurotoxicity (67). This is because IL-6 receptor blocking antibodies broadly used as the standard procedure for the clinical management of severe CRS cannot penetrate the BBB which results in their inability to induce complete CAR-T-related encephalopathy syndrome (CRES) remission (67). Furthermore, CRS and CRES are the major safety-related issues of CAR-T therapy which are caused by a rapid increase in the level of multiple cytokines, mainly IL-6, secreted by the activated infused CAR-Ts and mononuclear cells including dendritic cells and macrophages (68). In detail, target cell-induced IL-6 expression and production by CAR-Ts trigger factors that enhance monocyte production and release of IL-6 and other proinflammatory cytokines contributing to CRS and CRES progression (69). Therefore, some researchers have investigated a very novel strategy to address these limitations (69-71). It has been discovered that suppressing the IL-6 gene expression in CAR-Ts significantly decreases the IL-6 release from monocytes and it also reduces the possibility of severe CRS and CRES without reducing the antitumor efficacy of CAR-Ts in vitro and in vivo $(69,70)$. Therefore, one research group has generated a CAR construct with IL-6 shRNA (70). The shRNAIL6-modified CD19-redirected CAR-Ts (ssCAR-T-19) were delivered to a B-ALL patient with skin and testicle extramedullary relapse enrolled in a clinical trial (NCT03919240) (70). The patient was successfully treated by ssCAR-T-19s and this study proposed that these CAR-Ts might be therapeutically useful in efficiently eradicating infiltrating leukemia cells in the skin and testicle with a mild level of toxicity (however, broader patient populations and more careful clinical investigations are required for drawing substantiated conclusions) (70). Furthermore, ssCAR-T-19s have also been investigated in a recent clinical trial (NCT03064269) involving three patients with relapsed central nervous system (CNS) B-ALL (71). The results of this study demonstrated that ssCAR-T-19s can migrate into the CNS and reduce brain leukemic infiltration and significantly eradicate leukemic blasts in the cerebrospinal fluid (CSF) with mildly elevated cytokine levels and only grade 1 CRS (71). Therefore, 
this method could be proposed as an approach for reducing the risk of CRES in CAR-T therapy of patients with CNS B-ALL (71). However, in the case of severe CRS occurrence, IL-6 receptor blockade or IL-6 expression inhibition strategies are known to be inadequate approaches $(16,72)$. Therefore, it is necessary to use high-dose corticosteroid drugs to efficiently control the progression of life-threatening CRS $(16,72)$. Moreover, recent studies have shown that corticosteroids do not influence the efficacy and kinetics of CAR-Ts in the treatment of B-ALL (73). Additionally, TO-207 is an investigational drug that can inhibit the abnormal activation of macrophages and monocytes with no negative effects on the activity of T cells (74-77). In vitro studies have demonstrated that $\mathrm{TO}-207$ acts as a multi-cytokine inhibitor by suppressing monocyte-mediated secretion of IL-6 and other inflammatory cytokines (including IL-1 13 , monocyte chemoattractant protein 1 (MCP-1), IL-8, IL-18, and GM-CSF) without deteriorating CAR-T functionality $(74,78)$. Furthermore, IL-1 receptor blockade using the IL-1 receptor antagonist immunosuppressive drug anakinra has been an effective approach resulting in encouraging preclinical outcomes by preventing both lethal neurotoxicity and CRS (67). The same study has also claimed that anakinra and tocilizumab exhibit the same level of effectiveness in IL-6 signaling blockade and lethal CRS prevention in preclinical models (67). Moreover, CAR-Ts particularly engineered to secrete IL-1 receptor antagonists have also been investigated in preclinical studies (66). The results have indicated that IL-1 receptor antagonist-secreting CAR-Ts can prevent or mitigate CRS as well as neurotoxicity in a very efficient manner (66). As discussed, IL-1 blockade strategies can be efficiently utilized to prevent life-threatening CAR-T-related toxicities including CRS and neurotoxicity (66). However, it is important to mention that conducting clinical investigations with a high number of patients is a vital step in further validating the preclinical and clinical outcomes discussed in this section.

\subsubsection{GM-CSF Blockade}

Neurotoxicity and CRS development after CAR-T therapy are directly related to in vivo $\mathrm{T}$-cell expansion and subsequent secretion of T-cell effector cytokines such as IL-6, IFN- $\gamma$, GMCSF, and MCP-1 suggesting that even monocytes and macrophages may have contributions in the emergence of such adverse events $(15,79-82)$. Therefore, the neutralization of such cytokines may be a potential strategy for the management of these CAR-T-related toxicities $(79,83,84)$. GM-CSF neutralization reduces the secretion level of CRS-mediating cytokines such as IL-6, IL-8, and MCP-1 (79, 83, 84). Therefore, reductions in the level of these immune cell trafficking mediators can decrease the number of CNSinfiltrating immune cells which results in a reduced level of neuroinflammation (NI) and CRS $(79,83,84)$. Sterner et al. have evaluated the effects of GM-CSF neutralization on the functionality of CD19-redirected CAR-Ts using lenzilumab and they have demonstrated that lenzilumab does not inhibit the function of the CAR-Ts (79). Moreover, they have reported enhanced CD19-redirected CAR-T proliferation and durable control of leukemic disease in patient-derived xenograft (PDX) models after lenzilumab-mediated neutralization of GM-CSF (79). Additionally, these researchers expanded their experimental zone by generating CRISPR-Cas9-mediated GMCSF secretion-deficient (GM-CSF ${ }^{\mathrm{k} / \mathrm{o}}$ ) CD19-redirected CAR-Ts (79). These GM-CSF ${ }^{\mathrm{k} / \mathrm{o}}$ CAR-Ts were capable of maintaining their normal functions, exhibiting enhanced in vivo tumoricidal activity, and improving OS as compared with conventional CD19-redirected CAR-Ts (79). Other studies have used other genome-editing strategies such as the transcription activator-like effector nuclease (TALEN) for the same aim (85). They have demonstrated that their GM-CSF ${ }^{\mathrm{k} / \mathrm{o}}$ CAR-Ts can mediate a substantially reduced secretion level of GM-CSF leading to a disrupted or decrease macrophage-dependent secretion of CRSmediating factors such as MCP-1, IL-6, and IL-8 (85). Moreover, CAR-Ts can be engineered to be deficient in GM-CSF expression and produce anti-GM-CSF mAbs. The mentioned findings demonstrate that GM-CSF inhibition might be considered as a potential option for the abrogation of CRS and NI and enhancement of CAR-T function (79). However, it is safe to conclude that in-depth clinical assessments might help researchers understand the suitability of such strategies in clinical settings.

\subsubsection{Catecholamine Blockade}

Myeloid-derived catecholamines are known as crucial mediators of CRS (86-88). Macrophages secrete and respond to catecholamines via their adrenergic receptors upon encountering inflammatory stimuli (86-88). This mechanism results in an increase in the level of cytokine production and secretion (87-89). Therefore, high levels of circulating catecholamines can lead to excessive inflammatory responses (87-89). It has been found that disrupting the key enzymes involved in the synthesis of catecholamines can reduce its circulating level and prevent CRS occurrence (90, 91). For example, myeloid-specific deletion of tyrosine hydroxylase (TH) using metyrosine (MTR) can reduce the excessive level of this key CRS mediator without impairing CAR-T antitumor activity (91). Additionally, atrial natriuretic peptide (ANP) can also significantly reduce the circulating level of catecholamines without any interference with CAR-T-mediated therapeutic responses (90).

\subsubsection{Application of JAK Inhibitors}

As key CRS modulators, inflammatory cytokines including ILs, IFNs, and several growth factors crucially require the JAK tyrosine kinase family for their downstream signaling pathway (92-99). Therefore, the inhibition of the JAK family components can lead to a reduced CRS-related cytokine level (92-99). Itacitinib (INCB039110) is a JAK1 inhibitor that is being evaluated in clinical trials for the treatment of GvHD (NCT02614612) (99) and in preclinical investigations for the treatment of inflammatory and autoimmune diseases $(97,98)$. Itacitinib has also been evaluated in combination with other drugs for the treatment of various B-cell malignancies in clinical trials (NCT02018861 and NCT01905813) (95, 96). Recently, studies have evaluated the effects of prophylactic itacitinib in the prevention of CAR-T therapy-mediated CRS, and they have 
found that itacitinib does not impair CAR-T functionality both in vitro and in vivo and it significantly reduces CRS-associated cytokine levels in a dose-dependent fashion (94). Such data suggest the potential of itacitinib as prophylactic therapy for the prevention of CAR-T-related CRS as other studies investigated its various safety aspects (93). Additionally, ruxolitinib is also another JAK inhibitor that has recently been used as adjuvant therapy in a case report study involving a patient with B-ALL (92). Ruxolitinib has been successful in controlling corticosteroid-resistant CRS without interfering with CAR-T functionality (92). Such studies highlight the role of JAK inhibitors in the prevention and control of CRS and pave the way for more in-depth preclinical and clinical investigations.

\subsubsection{Intrathecal (IT) Chemotherapy}

IT chemotherapy has been used for controlling refractory CART-associated ICANS that is non-responsive to steroids (100, 101). Shah et al. have administered IT chemotherapy to two CAR-T-receiving patients and demonstrated that it can mediate rapid ICANS resolution without any long-term complications (100). This method can also accelerate the recovery process and reduce the complications of systemic long-term corticosteroid administration (100). Moreover, Yucebay et al. have also reported similar results from a study where IT chemotherapy resulted in the resolution of high-grade neurotoxicity (grade 3-4) of CD19-redirected CAR-T-receiving patients while corticosteroid therapy was inefficient (101). However, both of these studies suggest that this method requires detailed evaluations in future clinical trials $(100,101)$.

\subsubsection{Pretreatment With Antibody-Based Immunotherapy}

The occurrence of CRS and neurotoxicity seem to have a direct relationship with the disease burden of patients receiving CAR-T therapy $(14,16,17)$. Pretreating patients with antibody-based immunotherapy such as blinatumomab or inotuzumab ozogamycin (IO) before the administration of CAR-Ts has been known to potentially reduce disease bulk, thus minimizing the incidence and severity of the mentioned toxicities (102). Blinatumomab is a T-cell-redirecting bispecific antibody (TRBA) that can potentially mediate the elimination of leukemic cells through the engagement of endogenous $\mathrm{T}$ cells by simultaneously binding to CD19 on the surface of B-lineage cells and CD3 on cytotoxic T cells (103). Moreover, IO is an antibodydrug conjugate consisting of a humanized mAb against CD22 conjugated to the cytotoxic antibiotic agent ozogamycin (104). These therapeutic antibodies have shown considerably improved OS rates in comparison with standard therapy $(103,104)$. Additionally, one study including five adult patients with BALL (NCT02772198) has reported that treatment of R/R B-ALL patients with blinatumomab and/or IO before the beginning of CD19-redirected CAR-T therapy can result in promising response rates (with two out of five patients (40\%) achieving minimal residual disease (MRD)-negative $\mathrm{CR}$ and two other patients (40\%) achieving MRD-positive CR) (102). However, further investigations involving broader patient populations are required for a better understanding of the action mechanisms of antibody-based treatments before CAR-T therapy and their effects on the final clinical outcomes.

\subsubsection{Therapeutic Plasma Exchange (TPE)}

Recently, it has been shown that TPE (Figure 2A) in combination with glucocorticoid therapy can result in the gradual resolution of the CRS-related symptoms of CAR-T therapy recipients $(105,106)$. These findings suggest that this strategy can be a feasible procedure, at least in patients with severe CRS (grade $\geq 3$ ), even though TPE is not included in CRS management guidelines $(105,106)$. In a case report, Xiao et al. reported that in a 23-year-old male R/R B-ALL patient, after performing TPE along with the administration of dexamethasone, CRS (grade 3) was mitigated and controlled whereas treatment with antiallergic and antipyretic drugs, glucocorticoids, and tocilizumab was not effective against the progressing condition of the patient's CRS (105). Moreover, another case report has also reported that TPE has been effective in the treatment of CAR-T-induced CRS of a 4-yearold female patient with R/R B-ALL (107). Additionally, the report of a clinical trial (NCT02349698) involving ten patients has indicated that tocilizumab, glucocorticoid, and TPE have been effective in the successful controlling of severe CRS (grade 3-4) developed in four of the patients (108). However, the broader application of this approach for the management of CAR-T-related CRS lies in the outcomes of more comprehensive future clinical studies in this regard.

\subsubsection{Hemofiltration}

Hemofiltration (Figure 2B) has not been generally utilized as a clinical approach for controlling CAR-T therapy-related CRS. However, studies have used hemofiltration to help patients with high-grade CRS (grade $\geq 4$ ), with developed acute kidney injury, to recover their renal functionality (109). Moreover, a case report has indicated that hemofiltration has been helpful in mitigating severe CRS (grade 4) and preventing multiple organ failure and pulmonary infection in a B-ALL patient after CD19-redirected CAR-T therapy (110). It is important to state that in this case, tocilizumab and glucocorticoids were not successful in controlling the mentioned adverse events (110). Furthermore, another study has also proposed that continuous renal replacement therapy (CRRT) can be an additional approach for controlling CAR-T therapy-related CRS that is resistant to conventional treatment (111). This study has demonstrated that CRRT is effective in mitigating sepsis which has a similar pathophysiological mechanism to CRS (111). However, as such studies themselves indicate that there are still various unanswered questions in this field that require addressing (111).

\subsubsection{Fractionated CAR-T Infusion}

Recently, studies have indicated that there is a relationship between CAR-T infusion dose and the occurrence of CRS (112-114). Therefore, a fractionated dosing scheme can retain high response rates with acceptable tolerability in adult R/R BALL patients $(113,114)$. So far, two clinical trials have evaluated this strategy. The first study (NCT01029366) included R/R B- 


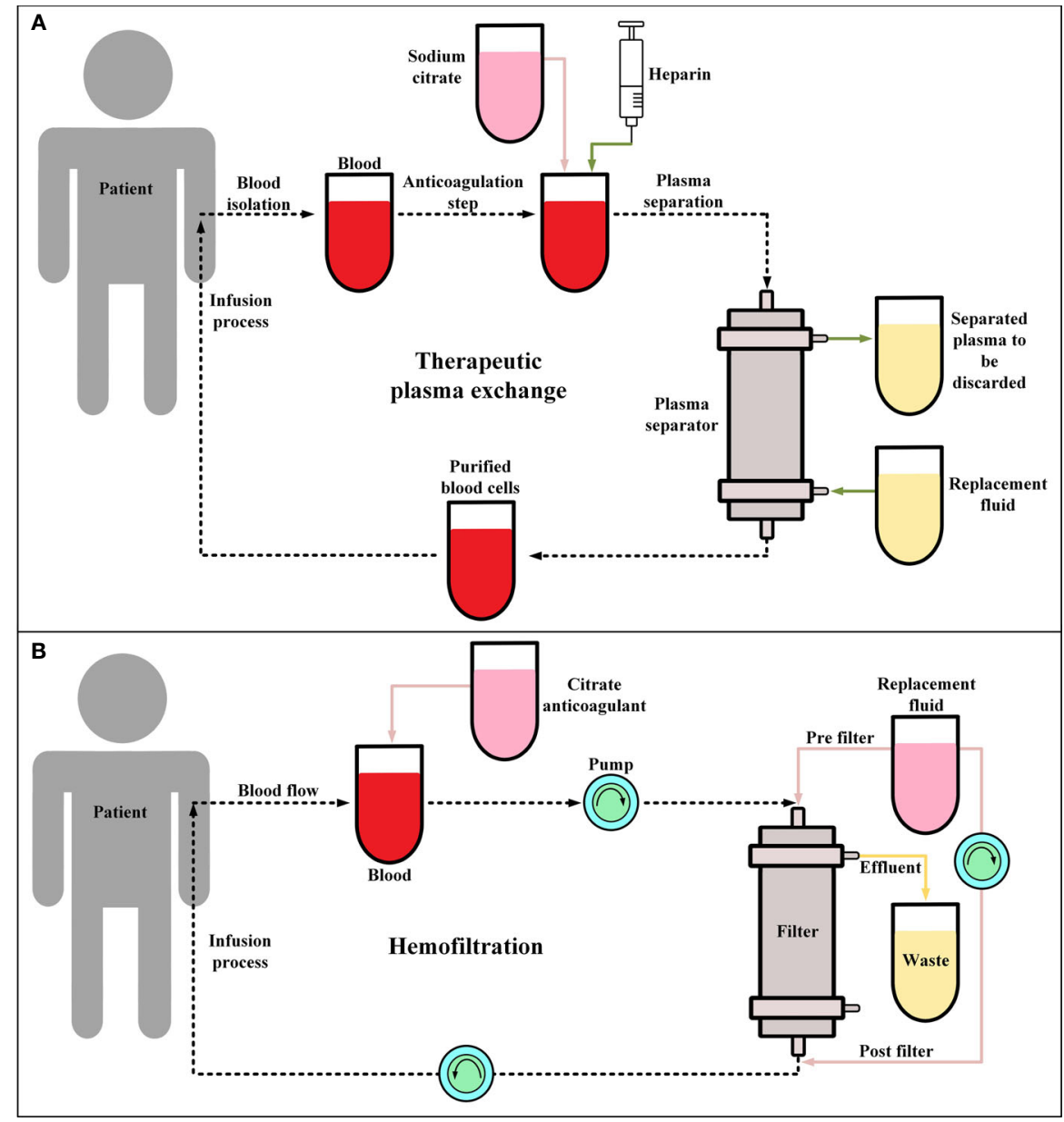

FIGURE 2 | Therapeutic plasma exchange (TPE) and hemofiltration. (A) The general procedure of TPE. Conventionally, in the anticoagulation step, sodium citrate or heparin are utilized. Moreover, the replacement fluid consists of albumin or fresh frozen plasma. (B) The procedure of continuous veno-venous hemofiltration (CWH) for hemofiltration. During CWH, a patient's blood is filtered by the means of highly semipermeable membranes (known as filter) and the ultrafiltrate (wastes) is separated by a process known as convection. Of note, the replacement fluid is added prior to or after hemofiltration.

ALL patients alongside patients with other CD19-positive malignancies and the second one (NCT02030847) only included adults with $\mathrm{CD} 19^{+} \mathrm{R} / \mathrm{R}$ B-ALL $(113,114)$. In detail, Frey et al. administered tisagenlecleucel to adult R/R B-ALL patients after lymphodepletion as either a one-time infusion or fractionated infusions split over 3 days $(10 \%$ on day $1,30 \%$ on day 2 , and $60 \%$ on day 3) (113). The total planned CAR-T infusion dose in their study varied with adaptive protocol modifications in response to efficacy and CRS occurrence (113). The second clinical trial included 35 patients in 3 different dosing cohorts which included the low-dose cohort $(9$ patients), the high-dose single infusion cohort (6 patients), and the high-dose fractionated (HDF) cohort (20 patients) (113). In the low-dose cohort, the patients received single or fractionated dosing, which resulted in manageable toxicity with a $33 \% \mathrm{CR}$ rate (113). In the high-dose single infusion cohort, half of the patients died due to refractory CRS (grade 4/5) and culture-positive sepsis, and the other half achieved CR (113). Moreover, the
HDF cohort had a $90 \% \mathrm{CR}$ rate and manageable CRS (grade $\leq 3$ ) (113). Of note, according to Penn Grading System for CRS, grade 4 is characterized by life-threatening complications including hypoxia which necessitates the appliance of mechanical ventilation and hypotension requiring the administration of high-dose antihypotensive agents. Also, grade 5 is defined as CRS-caused mortality (113). The HDF scheme resulted in the highest survival rate with a 2 -year OS of $73 \%$ and event-free survival of $49.5 \%$ (113). The researchers of this study proposed that a fractionated dosing scheme of CTL019, for administration to adult R/R ALL patients, with intrapatient dose modifications can optimize the safety of B-ALL CAR-T therapy without impairing its efficacy (113). Additionally, these clinical trials have demonstrated that a fractionated dosing scheme, where day 2 and day 3 doses are held in response to early CRS, enables individualized dose modifications for achieving a better balance of efficacy and safety in comparison with protocols suggesting a defined single-dose infusion (113). 


\subsection{Overcoming Graft Rejection}

Using autologous CAR-Ts in clinical settings may not always be feasible since the patients may be under different types of treatments and may have malignancies with various levels of severity which might imping on the quality of the final T-cell products and the corresponding clinical outcomes (115). Considering these limitations, allogeneic CAR-Ts, generated from donor-derived $\mathrm{T}$ cells, can be used as an alternative even though they tend to have their limitations (115). Such limitations include causing alloreactivity-related adverse events such as host-versus-graft $(\mathrm{HvG})$ and graft-versus-host $(\mathrm{GvH})$ reactions (115). In this section, we will review studies focusing on developing strategies for addressing these limitations.

\subsubsection{Conditioning Regimen}

Conditioning regimen, also known as lymphodepleting conditioning regimen, is the occasional use of chemotherapeutic agents in cell-based cancer therapies such as CAR-T therapies (regardless of autologous or allogeneic CAR-T therapies) (116). It has been demonstrated that conditioning regimen is an important factor affecting the clinical outcomes of CAR-T therapy (116). Studies have demonstrated that conditioning regimen prior to adoptive cell transfer significantly enhances the efficacy of therapies with ex vivo-expanded tumor-infiltrating lymphocytes (TILs) (117). In brief, lymphodepletion chemotherapy provides an appropriate environment for infused T cells to expand by helping create a supportive space in the immune system of the recipients (116-119). Lymphodepleting conditioning regimen acts by several mechanisms including eliminating the recipients' $\mathrm{T}$ and $\mathrm{B}$ lymphocytes as well as NK cells, the eradication of immunosuppressive cells such as regulatory $\mathrm{T}$ cells and myeloidderived suppressor cells, inducing co-stimulatory molecules and downregulating indoleamine 2,3-dioxygenase (IDO) in tumor cells, the elimination of homeostatic cytokine sinks such as IL-2, IL-7, and IL-15, and finally promoting the expansion, function, and persistence of the adoptively transferred $\mathrm{T}$ cells by eliminating the factors interfering with their activity (117-119).

Fludarabine and cyclophosphamide are two chemotherapeutic agents that are occasionally used as the conditioning regimen for BALL patients receiving CAR-T therapy $(120,121)$. Studies have demonstrated that using the combination of these drugs in the lymphodepleting conditioning regimen would result in improved CD19-redirected CAR-T expansion and persistence, better clinical outcomes, and disease-free survival of the patients in comparison with non-fludarabine lymphodepleting regimens $(120,121)$. Others have shown a relationship between elevated in-serum IL-15 levels and clinical response after CD19-redirected CAR-T therapy (122). It is also believed that the probability of achieving a favorable cytokine profile is higher in patients who receive high-intensity lymphodepletion in comparison with those that receive lowintensity lymphodepletion (123). This occurrence in turn is associated with better clinical outcomes (123).

\subsubsection{Using Genome-Editing Methods}

Genome-editing technologies have been utilized for addressing the unfavorable limitations of using allogeneic T cells (124-127).
In this regard, Torikai et al. have utilized the zinc finger nuclease (ZFN) genome-editing technique to eliminate the expression of the endogenous $\alpha \beta$ TCR in allogeneic CD19-redirected CAR-Ts (128). They demonstrated this method can prevent allogeneic CAR-T-mediated GvHD without compromising CAR-T functionality or antitumor activity (128). Stepping further, they used the same genome-editing method and disrupted the expression of HLA-A in CD19-redirected CAR-Ts, and demonstrated that this strategy can protect CAR-Ts from lymphodepletion therapy, alongside eliminating the possibility of GvHD (129).

Other researchers have developed practical platforms to demonstrate the applicability of the TALEN genome-editing technique for the production of "off-the-shelf" allogeneic CARTs (130-132). In this regard, Poirot et al. used TALEN for the simultaneous disruption of two genes in allogeneic CAR-Ts (130). First, the researchers disrupted the TCR $\alpha$ constant (TRAC) gene expression which resulted in the elimination of TCR $\alpha \beta$ expression; therefore, it abrogated the potential of the allogeneic CAR-Ts for GvHD mediation (130). The second knock-out was aimed at rendering the universal allogeneic CAR-Ts resistant to destruction by a lymphodepleting or immunosuppressive agent (130). CD52, as the second knockout target, can be specifically targeted using the lymphodepleting $\mathrm{mAb}$ alemtuzumab, thus enabling the lymphodepletion of recipient(s) and the creation of a receptive environment concurrently or before the administration of the TCR/CD52knock-out CD19-redirected CAR-Ts (130). Poirot et al. demonstrated that the TCR/CD52-knock-out CD19-redirected CAR-Ts were capable of efficient elimination of $\mathrm{CD} 19^{+}$tumor targets even while accompanied by the chemotherapeutic agent (130). Taken together, this GMP-compatible scalable process can be considered as a general platform for the manufacturing of "off-the-shelf" CAR-Ts from the T cells of healthy third-party donors (130). Similarly, Qasim et al. also generated allogeneic TCR/CD52-knock-out CD19-redirected CAR-Ts from nonHLA matched donors, and demonstrated that these genomeedited universal allogeneic CAR-Ts did not mediate alloreactivity in infant recipients with R/R B-ALL (132). They also reported that these CAR-Ts mediated molecular remission in the recipients with acceptable persistence while being anti-CD52 therapy-resistant (132). Moreover, other researchers have also demonstrated that simultaneous knock-out of TCR $\alpha \beta$ expression and deoxycytidine kinase $(\mathrm{dCK})$ can result in the production of allogeneic CD19-redirected CAR-Ts that do not mediate GvHD and are resistant to dCK phosphorylationdependent lymphodepleting regimens (131).

It is worth mentioning that the results of two Phase I trials using TCR-knockout CD19-redirected CAR-T therapy in both children and adults (NCT02808442 and NCT02746952, respectively) have demonstrated the practicability of using allogeneic genome-edited CAR-Ts for the treatment of patients with R/R B-ALL (133). The results of such trials indicate that allogeneic CAR-Ts can mediate acceptable tumoricidal activity with manageable levels of toxicities and adverse events (133). Such CAR-Ts can be beneficial for the treatment of heavily 
pretreated R/R B-ALL patients with rapidly progressing diseases since autologous CAR-Ts may not be accessible in these cases in terms of meeting the adequate cell number or final-product quality (133).

In addition to the abovementioned strategies, CRISPR-Cas9based genome-editing method can also be utilized for the generation of universal allogeneic CAR-Ts (134-137). One study has used CRISPR-Cas9 to selectively insert the CD19redirected CAR transgene into the TRAC locus (134). This mechanism results in the deficiency of the endogenous TCR expression and it ameliorates in vivo CAR-T functionality while reducing the risk of alloreactivity as compared with retrovirusmediated random CAR transgene insertion (134). It also postpones the effector $\mathrm{T}$-cell differentiation and exhaustion of CAR-Ts and facilitates the efficient internalization and consequent re-expression of CAR molecules upon multiple target antigen engagement (134). MacLeod et al. made a similar attempt and demonstrated that their TCR-knock-out CD19-redirected CAR-Ts exhibited superior antitumor activity in preclinical mouse models without mediating GvHD (136). Furthermore, researchers incorporated multiple gRNAs into a CAR-encoding lentiviral vector which resulted in the simultaneous knock-out of the endogenous TCR and Beta-2 microglobulin (b2M) of HLA class I, thereby paving the way for a practical strategy for the production of universal allogeneic CARTs (137).

More recently, Georgiadis et al. demonstrated that incorporation of an sgRNA element into the Delta U3 3' long terminal repeat (LTR) of their CAR-encoding lentiviral vector would result in the production of a self-inactivating lentiviral terminal vector that combines CAR expression with CRISPR-Cas9 effects (135). In detail, after transcription and duplication of the hybrid DU3sgRNA and electroporation-facilitated delivery of Cas 9 mRNA, this platform cleaves the TRAC locus and enables enriching the TCR-knock-out CAR-T population using automated magnetic separation (135). These CAR-Ts would retain their CARassociated specificity and antileukemic activity, have superior persistence as compared with their conventional counterparts, and would not mediate alloreactivity in the respective recipients (135). However, despite what we have discussed, a recent study by Stenger et al. has indicated that CD19-redirected CAR-Ts harboring endogenous TCR have superior persistence and mediate considerably prolonged leukemia control in vivo as compared to their CRISPR-Cas9-mediated TCR-knockout counterparts (138). Conclusively, it can be mentioned that more clinical information is required for drawing more substantiated conclusions.

\subsubsection{Virus-Specific T Lymphocytes (VSTs) for CAR Expression}

VSTs that harbor their native TCRs can be used as a source of universal allogeneic $\mathrm{T}$ cells in CAR-T therapy $(139,140)$. Tabelecleucel (tab-cel ${ }^{\circledR}$ ) is a universal allogeneic $\mathrm{T}$-cell immunotherapy using Epstein-Barr virus (EBV)-specific T cells that harbor TCRs specifically targeting EBV antigens $(139,140)$. It has been demonstrated that CD19-redirected CAR-Ts generated using EVB-specific $\mathrm{T}$ cells are well-tolerated with poor mediation of GvHD and CRS suggesting a promising approach for generating universal allogeneic CAR-Ts (140).

VSTs are now being investigated for the prevention of viral infections in recipients of hematopoietic stem cell transplantation (HSCT) since these cells can reconstruct the recipients' impaired immune system and confer immunity against life-threatening viral infections after HSCT without GvHD mediation $(141,142)$. This feature of VSTs has encouraged researchers to use them as a reliable source for the generation of allogeneic CAR-Ts $(142,143)$. An ongoing Phase I clinical trial (NCT00840853) has studied VSTs genetically engineered to express CD19-redirected CARs to see if these cells can maintain their antiviral activity alongside exhibiting specific tumoricidal functionality in patients with CD $19^{+}$B-ALL after HSCT (142). According to the results of this clinical trial so far, the investigators stated that these CAR-Ts induced no infusion-related toxicities (142). The researchers have also added that vaccinating the recipients of these CAR-Ts with viral antigens may result in enhanced CAR-T expansion and antitumor activity (142). However, this clinical trial is planned to be completed in 2031; therefore, more accurate clinical outcomes can be obtained by then.

\subsubsection{Human Induced Pluripotent Stem Cell (hiPSC)-Derived CAR-Ts}

Lately, hiPSC-derived CAR-Ts have gained a great deal of attention as universal allogeneic CAR-Ts (144, 145). In detail, peripheral blood-derived $\mathrm{T}$ cells are converted to hiPSCs and genetically engineered to express the CD19-redirected CAR with targeted integration into the TRAC locus followed by clonal selection carried out for generating a master hiPSC line, termed TRAC-TiPSC $(144,145)$. These cells are also genetically manipulated to express a high-affinity form of CD16 with proteolytic resistance for addressing tumor antigen escape (144, 145). The mentioned characteristics of hiPSC-derived CAR-Ts render them incapable of GvHD mediation $(144,145)$. Taken together, the researchers of these studies indicated that since such CAR-Ts mediated encouraging preclinical results as an effective and safe allogeneic product, it might be feasible to evaluate these CAR-Ts in a Phase I clinical trial in patients with B-cell neoplasms $(144,145)$.

\subsubsection{Placenta Blood-Derived T Cells for CAR Expression}

Recently, researchers have demonstrated that $\mathrm{T}$ cells isolated from postpartum human placenta/umbilical cord blood can be used for the generation of CD19-redirected CAR-Ts, termed PCD19-redirected CAR-Ts (146). P-CD19-redirected CAR-Ts are mainly naïve $\left(\mathrm{CD}_{4} 5 \mathrm{RA}^{+}\right) \mathrm{T}$ cells and retain their naïve/memory marker expression and harbor a lower expression of effector/ exhaustion markers as compared to peripheral blood mononuclear cell-derived CAR-Ts (146). Moreover, these cells also have superior immune tolerance to HLA mismatch and exhibit weakened allogeneic activation resulting in a lower GvHD occurrence possibility (146). Researchers have suggested that these features of P-CD19-redirected CAR-Ts make them a 
promising candidate for universal allogeneic CAR-T therapy (146). It is worth mentioning that the endogenous TCR expression of these $\mathrm{T}$ cells can be abrogated using the CRISPR genome-editing technique to minimize the risk of endogenous TCR-mediated GvHD (146).

\subsubsection{Alloimmune Defense Receptor (ADR)}

One strategy for overcoming the issue of cellular immune rejection is the abrogation of immune responses mediated by both activated alloreactive T cells and NK cells that direct the elimination of foreign cells through different mechanisms (147151). Mo et al. have developed an engineered receptor called ADR that mediates the depletion of activated host $\mathrm{T}$ and NK cells through selective recognition of the cell surface receptor 4-1BB since this molecule is temporarily upregulated on the cell surface of activated $\mathrm{CD}^{+} \mathrm{T}$ cells and $\mathrm{CD}^{+} \mathrm{T}$ cells, as well as NK cells (151). The 4-1BB-specific chimeric ADR is composed of a 4$1 \mathrm{BB}-$ recognizing fragment derived from 4-1BB ligand (4-1BBL) that is connected to the intracellular $\mathrm{CD} 3 \zeta$ chain through a spacer and a TM region (151). In vitro and in vivo results have indicated that ADR-expressing $\mathrm{T}$ cells manage to resist cellular rejection by targeting alloreactive lymphocytes and, on the other hand, they manage to spare resting lymphocytes (151). Furthermore, Mo et al. co-expressed ADR alongside secondgeneration CD19-redirected CARs, and demonstrated that $\mathrm{T}$ cells co-expressing these two chimeric receptors can preserve their independent anti-rejection and antitumor functionality (151). Moreover, T cells expressing only CD19-redirected CARs and $\mathrm{T}$ cells co-expressing both CD19-redirected CARs and ADRs have exhibited similar cytotoxic profiles against $\mathrm{CD}_{19^{+}}$cells, according to Mo and colleagues (151). Conclusively, these researchers have proposed that coexpression of CARs and ADRs can mediate sustained tumor eradication and produce long-term therapeutic benefit in immunocompetent recipients with hematologic malignancies alongside enabling the generation of rejection-resistant off-theshelf allogeneic CAR-Ts (151).

\subsubsection{HLA-Matched or HLA-Haploidentical CAR-Ts}

Using HLA-matched or HLA-haploidentical allogeneic CAR-Ts can lead to different clinical outcomes in B-ALL CAR-T therapy (106). Researchers have investigated the use of HLA-matched or HLA-haploidentical allogeneic CD19-redirected CAR-Ts (MCAR-Ts and H-CAR-Ts, respectively) for the treatment of $\mathrm{R} / \mathrm{R}$ B-ALL patients to evaluate which one can result in better clinical outcomes (106). Recently, Jin et al. described the first-in-human application of M-CAR-Ts in R/R B-ALL patients before allogeneic hematopoietic stem cell transplantation (allo-HSCT) (106). The results of this investigation demonstrated that using M-CAR-Ts for the treatment of R/R B-ALL patients results in higher $\mathrm{CR}$ rates but it also leads to more severe toxicities in comparison with using H-CAR-Ts (106). These researchers also reported that the mild infusion-related toxicities occurring in patients receiving $\mathrm{H}$-CAR-Ts enabled using higher dose infusions in these patients in comparison with the patients receiving M-CAR-Ts (106). It is important to mention that even though these researchers did not observe GvHD or any uncontrolled infusion-related toxicities, there is still a need for paying considerable attention to GvHD and other infusionrelated toxicities (106). Other researchers have also investigated the use of H-CAR-Ts (152-154). In particular, Cai et al. and Zhang et al. have reported that using H-CAR-Ts has beneficial therapeutic effects as part of a conditioning regimen for alloHSCT $(152,153)$. However, it is suggested that, as compared to M-CAR-Ts, the lower efficacy of H-CAR-Ts may be due to their heterogeneity in mediating graft rejection (106). Additionally, it is yet to be discovered that whether using a stronger immunosuppressive treatment before the infusion of H-CARTs can enhance the efficacy and antitumor activity of these cells (106).

\subsection{Overcoming B-Cell Aplasia and Its Consequences}

$\mathrm{B}$-cell aplasia, as characterized by the low number or the absence of B cells, is commonly considered as an indicator of a successful CD19-redirected CAR-T therapy which can last for as long as CAR-Ts are potentially functional (29). B-cell aplasia can lead to agammaglobulinemia and hypogammaglobulinemia resulting in an increased risk of sinopulmonary and various other lifethreatening infections due to the inability of the patients' immune system to produce antibodies (29). Prevention of serious bacterial infections in patients with hypogammaglobulinemia after CD19-redirected CAR-T therapy and also in patients with primary immunodeficiency (PID) who suffer from impaired immune systems can be achieved through immunoglobulin replacement $(14,15,155-158)$. Increasing the level of serum immunoglobulin G (IgG) has been correlated with a considerably lower risk of sinopulmonary infection (29). Serum IgG level of more than $1000 \mathrm{mg} / \mathrm{dL}(720 \mathrm{mg} / \mathrm{dL}$ to $1430 \mathrm{mg} / \mathrm{dL}$ IgG level for maintaining an infection-free state) has been known as the optimal concentration needed to provide patients with protection against infections (29). Furthermore, subcutaneous immunoglobulin (SCIg) replacement can be considered as a suitable method for the stabilization of IgG levels, the improvement of health-related quality-of-life scores, and minimizing systemic side effects with increased ease of administration and affordability in comparison with intravenous immunoglobulin (IVIG) replacement (159-163). Moreover, antimicrobial prophylaxis including levofloxacin for gramnegative bacteria in patients with neutropenia can be beneficial in the prevention of bacterial infections in patients receiving CD19redirected CAR-T therapy $(25,164,165)$. Similarly, antifungal prophylaxis such as micafungin or fluconazole for Candida species in patients with neutropenia and pentamidine or sulfamethoxazole for Pneumocystis jiroveci are among common recommendations for fungal infection prevention $(25,164,165)$. Also, in the case of viral infections, antiviral prophylaxis such as acyclovir is used for controlling herpes simplex virus (HSV)- and varicella-zoster virus (VZV)-related viral infections after CD19redirected CAR-T therapy $(25,164,165)$. Moreover, a recent study has reported prolonged severe acute respiratory syndrome coronavirus 2 (SARS-CoV-2) infection in a patient who had received BCMA-redirected CAR-T therapy (166). Hensley et al. 
stated that even though convalescent plasma therapy and the antiviral agent remdesivir was used as treatment options, the patient ultimately died from complications related to this infection (166).

\subsection{Overcoming Unintentional Transduction of Leukemic Cells}

Unintentional transduction of B-ALL blasts with the CAR transgene during the manufacturing process of CAR-Ts is a rare incidence that leads to the aberrant expression of the CD19redirected CARs by leukemic cells rendering them resistant to CAR-T-mediated tumor cell eradication (Figure 3) (167). Upon this incidence, a mechanism of resistance is conferred through cis binding of the CD19-redirected CAR to the CD19 epitope on the surface of leukemic cells, thus masking the target antigen from being recognized by CD19-redirected CAR-Ts (167). Therefore, the patient in which this incidence was documented for the very first time experienced $\mathrm{CD} 19^{-}$disease relapse and underwent salvage chemotherapy, anti-CD22 antibody therapy, and CD22-directed CAR-T therapy (167). However, the patient ultimately died from the complications associated with progressive leukemia (167).

Later in 2020, Ruella et al. developed an anti-CAR19 idiotype CAR ( $\alpha$ CAR19) to selectively target and eliminate CD19redirected $\mathrm{CAR}^{+}$cells (both $\mathrm{T}$ cells and unintentionally transduced leukemic cells) (168). This method entails the application of genetically modified T cells ( $\alpha$ CAR19) that express CARs that recognize CD19-redirected CAR ${ }^{+}$cells (168, 169). It has been demonstrated that the $\alpha$ CAR $19 \mathrm{~T}$ cells can successfully kill both CD19-redirected CAR-expressing leukemic cells and T cells (168). It is worth mentioning that no evidence of reverse killing of $\alpha$ CAR19 $\mathrm{T}$ cells by CD19-redirected CARexpressing $\mathrm{T}$ cells has been observed (168). These findings demonstrated that $\alpha$ CAR19 T cells can act as "cellular antidotes" and a safe depletion strategy to eliminate common CAR-T engraftment side effects such as prolonged B-cell aplasia and other yet-to-be-known complications as well as CARexpressing leukemic cells $(168,170)$. However, broader investigations are still required to safely conclude that this strategy may be efficient in controlling this important unintentional side effect.

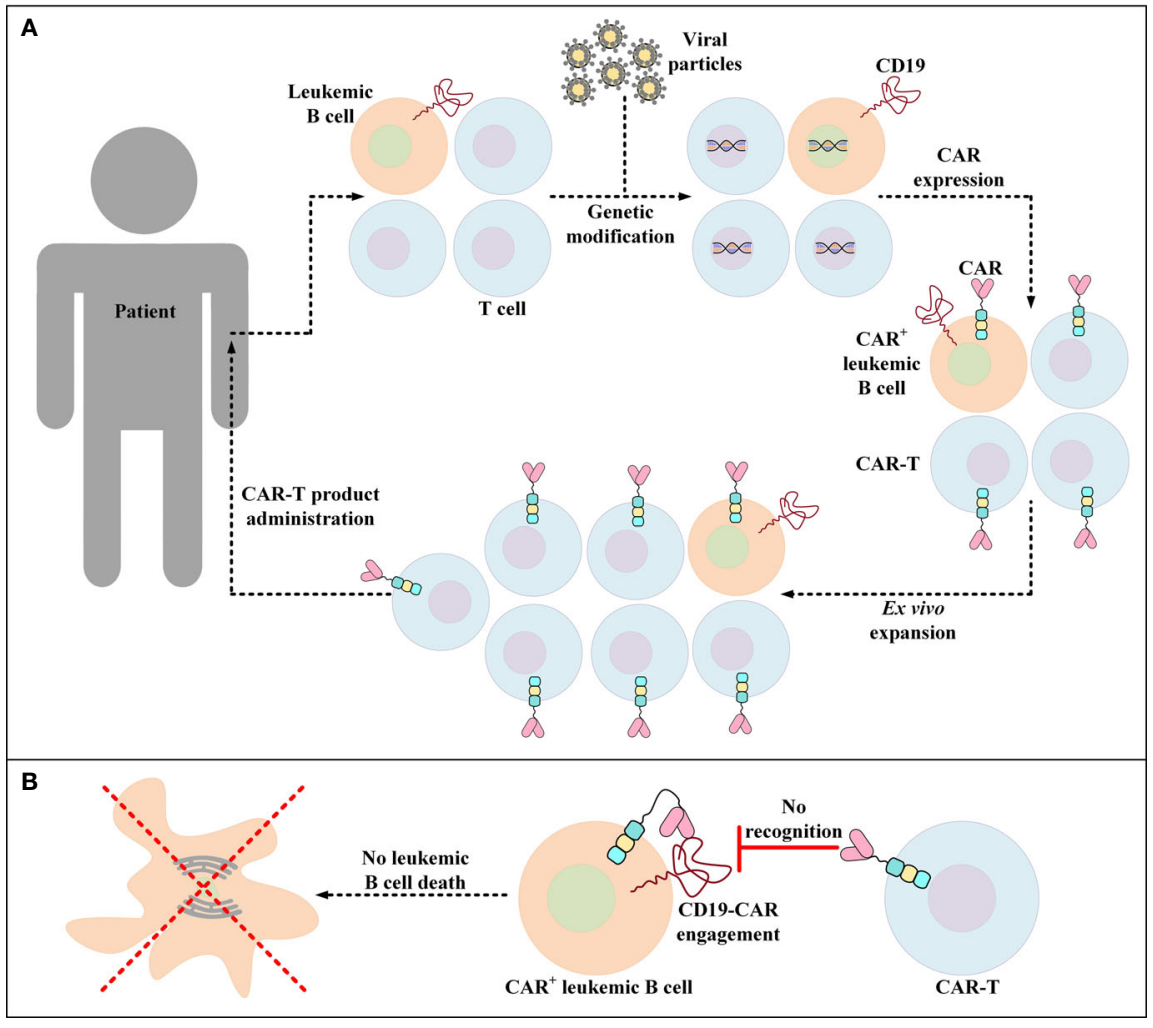

FIGURE 3 | Accidental transduction of leukemic B cells and the emergence of resistance to CAR-T therapy. (A) Accidental transduction of leukemic B cells during the process of CAR-T preparation. An error in the isolation of T cells leads to the contamination of the cell pool with leukemic $B$ cells. Moreover, in the process of genetic modification, leukemic B cells are transduced along with the isolated T cells for the expression of certain CD19-specific CARs. (B) Resistance of CAR ${ }^{+}$ leukemic cells to a particular CD19-redirected CAR-T product. Following the administration of the developed product into patients, CAR ${ }^{+}$leukemic cells become resistant to that particular CD19-redirected CAR-T product due to the engagement of their CD19 with their self-expressed CARs (a process known as epitope masking). This incident might also occur in the case of CAR-T products that target different target antigens than CD19. 


\subsection{Phenotype-Changing Factors}

The data from various studies propose that there is a strong correlation between the expansion rate of transferred CAR-Ts in the recipient and the subsequent clinical response (14, 24-27). It is also believed that the in vivo persistence of functional CAR-Ts is critical for disease relapse prevention (14, 24-27). The phenotypic composition of patient- or donor-isolated $\mathrm{T}$ cells and the reinfused product is among multiple factors affecting the in vivo expansion and persistence of CAR-Ts and the durability of their antitumor responses (Figure 4) (171). In this section, we will discuss various factors affecting the phenotype of CAR-Ts.

\subsection{1 $\mathrm{CD}^{+}: \mathrm{CD}^{+}$Ratio}

Different investigations have demonstrated that human $\mathrm{CD} 4^{+} \mathrm{T}$ cells and $\mathrm{CD}^{+}{ }^{+} \mathrm{T}$ cells consist of functionally and transcriptionally separate subsets with varied in vivo proliferation and persistence capacities after ex vivo expansion and adoptive transfer (172-177). Sommermeyer et al. have shown that human CD19-redirected CAR-Ts manufactured from purified $\mathrm{CD}^{+}$or $\mathrm{CD}^{+}$central memory $\mathrm{T}\left(\mathrm{T}_{\mathrm{CM}}\right)$ cells or naïve $\mathrm{T}\left(\mathrm{T}_{\mathrm{N}}\right)$ cells are more effective in attacking and killing $\mathrm{CD} 19^{+}$tumors in immunodeficient mice in comparison with CD19-redirected CAR-Ts manufactured from effector memory $\mathrm{T}\left(\mathrm{T}_{\mathrm{EM}}\right)$ cells (178). Other studies have also demonstrated that in comparison to $\mathrm{T}_{\mathrm{EM}}$ cells, $\mathrm{CD}^{+} \mathrm{T}_{\mathrm{CM}}$ cells harbor stemness potency alongside showing superior persistence after adoptive transfer $(172,179)$. This fact proposes the advantages of this subset for providing long-term persistence (172, 179). Moreover, in the first clinical trial assessing the feasibility of selecting and engineering defined T-cell subsets, Turtle et al. conducted a Phase I/II clinical trial to evaluate CD19-redirected CAR-Ts manufactured from separately modified defined $\mathrm{CD}^{+}{ }^{-} \mathrm{T}$-cell and $\mathrm{CD}^{+}$T-cell subsets (180). These researchers administered this product in a defined $\mathrm{CD} 4^{+}$: $\mathrm{CD}^{+}$composition and in a dose-escalation/de-escalation format to adult B-ALL patients after lymphodepletion chemotherapy (180). They found that the infusion of CAR-T comprised of a uniform ratio of $\mathrm{CD}^{+}: \mathrm{CD}^{+}$shows a correlation between cell dose and earlier and higher peak expansion of clonally diverse CAR-Ts (180). These findings had not been reported in other investigations in which CAR-Ts were manufactured and infused without the consideration of the $\mathrm{CD}^{+}: \mathrm{CD}^{+}$ratio (180). Their results also demonstrated that the infusion of a defined ratio of CD19redirected CAR-Ts manufactured from $\mathrm{CD}^{+} \mathrm{T}_{\mathrm{CM}}$ cells and $\mathrm{CD}^{+} \mathrm{T}$ cells could provide a synergistic improvement in potency (180). Also, the results of preclinical investigations in Raji tumor-bearing immunodeficient mice receiving CAR-Ts manufactured from distinct $\mathrm{T}$-cell subsets have shown that when either $\mathrm{CD}^{+}$CAR-Ts or $\mathrm{CD}^{+} \mathrm{CAR}-\mathrm{Ts}$ were excluded from the formulated product, the potency of the infused product was significantly reduced (178). It is safe to say that selecting a defined subset of $\mathrm{T}$ cells for CAR-T manufacturing with a uniform composition may provide reproducible potency in clinical therapy (180). Moreover, Biasco et al. have recently highlighted the impact of different clonal subtypes of $\mathrm{T}$ cells in the final CAR-T product on early antitumor responses and long-term disease-controlling capability of CAR-T therapy (181). These researchers stated that even though $\mathrm{T}$ memory stem cells $\left(\mathrm{T}_{\mathrm{SCM}}\right)$ have a low frequency in the final generated CAR-T product, these T-cell clones significantly contribute to the circulating CAR-T pools throughout both early proliferation and prolonged diseasecontrolling persistence (181). As suggested by Biasco et al., these findings underscore the significant role of $\mathrm{T}_{\mathrm{SCM}}$ in both early antileukemic CAR-T reactions and prolonged disease control (181). However, it is important to mention that CAR-T prolonged persistence, after achieving the desired clinical outcomes and disease control, might lead to cytopenia which should be taken into consideration (182).

\subsubsection{Ex Vivo Culture Media}

The different cell culture media formulations used for the activation and expansion of $\mathrm{T}$ cells ex vivo, and eventually generating CAR-Ts can be optimized in many ways since they tend to have significant impacts on various aspects of the final Tcell product $(183,184)$. The cell culture media formulations

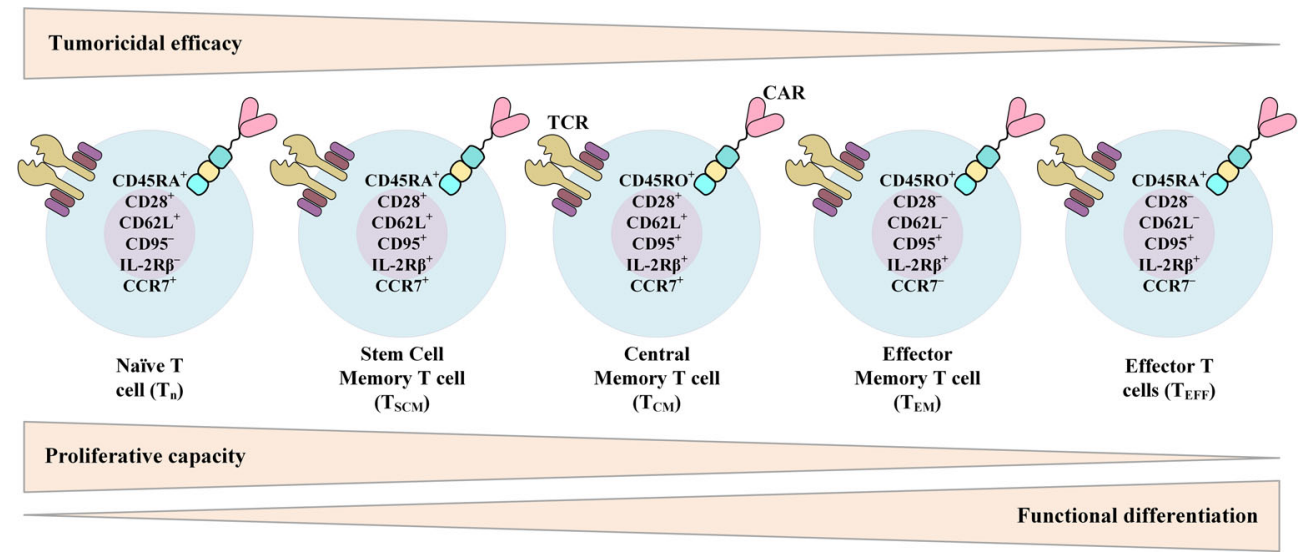

FIGURE 4 | Phenotypic characteristics of different T-cell (or CAR-T) subsets over the course of T-cell differentiation from naïv $T$ cells to effector $T$ cells ( $T_{E F F}$ ) and their relationship with the proliferative capacity, functional differentiation, and tumoricidal efficacy of T cells. CAR, chimeric antigen receptor; TCR, T-cell receptor. 
currently used are dependent on fetal bovine serum (FBS) or human serum (HS) $(183,184)$. Researchers have investigated the effects of the human transfusion-grade whole blood fractionderived concentrated growth factor extracts, named Physiologix $^{\mathrm{TM}}$ xeno-free (XF) hGFC (Phx), on CAR-T expansion and function $(183,184)$. This method has been developed to resolve the supply issues of FBS or HS $(183,184)$. It has been found that Phx enhances T-cell proliferation in both research and clinical-grade media and improves lentiviralmediated gene transferring and expression $(183,184)$. Moreover, CAR-Ts expanded ex vivo in Phx-conditioned media harbor advanced in vivo expansion and antitumor activity as compared to those of CAR-Ts expanded ex vivo in HS-conditioned media $(183,184)$. Phx also enhances the number of naïve $\mathrm{T}$ cells $\left(\mathrm{CD} 45 \mathrm{RO}^{-} / \mathrm{CCR}^{+}\right)$and central memory $\mathrm{T}$ cells $\left(\mathrm{CD} 45 \mathrm{RO}^{+} / \mathrm{CCR}^{+}\right)$in both $\mathrm{CD}^{+} \mathrm{T}$-cell and $\mathrm{CD}^{+} \mathrm{T}$-cell populations which contributes to higher persistence and durability of CAR-Ts resulting in better clinical outcomes (183, 184). Geiger and colleagues have also found that, upon T-cell activation, significant changes occur in the arginine metabolism resulting in a decline in the concentration of the intracellular Larginine (185). Therefore, these researchers demonstrated that supplementing $\mathrm{T}$-cell culture media with $\mathrm{L}$-arginine can increase the reduced intracellular L-arginine levels in activated $\mathrm{T}$ cells and it can induce oxidative phosphorylation instead of glycolysis (185). This effect can result in the central memory phenotype development (185).

The methods currently used for generating FDA-approved CAR-Ts include using anti-CD3 and IL-2 or anti-CD3 and antiCD28 beads (186). However, these methods result in the generation of CAR-Ts expressing exhaustion markers with an effector phenotype (186). Studies have demonstrated that using IL-7 and IL-15 during the ex vivo culturing of T cells would result in the production of CAR-Ts with $\mathrm{T}$ memory stem cell phenotype $\left(\mathrm{CD} 45 \mathrm{RA}^{+} / \mathrm{CCR}^{+}\right)$that exhibit superior tumoricidal activity, expansion, and persistence in vivo as compared with their counterparts expanded ex vivo using IL-2 (187). Others studies have also reported very similar results alongside adding that using IL-7 and IL-15 during the ex vivo culturing of $\mathrm{T}$ cells also elevates the response rate of the resultant CAR-Ts to anti-PD-1 adjuvant therapies which is mainly due to the anti-PD-1-responsive $\mathrm{CD}^{+} / \mathrm{CD} 2 \mathrm{~L}^{+} / \mathrm{TCF}^{+} / \mathrm{IRF}^{-}$ population of the CAR-Ts (188). However, Alizadeh et al. have indicated that $\mathrm{T}$ cells expanded with IL-15 preconditioning maintain a less differentiated stem cell memory phenotype $\left(\mathrm{CD} 2 \mathrm{~L}^{+} / \mathrm{CD} 45 \mathrm{RA}^{+} / \mathrm{CCR}^{+}\right)$with reduced levels of exhaustion marker expression in comparison with $\mathrm{T}$ cells preconditioned with IL-2. They have also stated that using IL-7 or IL-21 alongside IL-15 decreases the favorable influences of IL-15 in the induction of CAR-T phenotype and tumoricidal activity (189).

Additionally, it has been demonstrated that using human platelet lysate (HPL) as a supplement in the culture media of T cells results in a higher number of $\mathrm{T}$ cells with central memory phenotype in comparison with human $\mathrm{AB}$ serum (ABS)- or FBSsupplemented culturing media (190). It has also been discovered that the presence of various cytokines, such as IL-7, in HPL is responsible for the phenotypic differences observed in the mentioned study (190). Furthermore, Torres Chavez et al. have also obtained similar results indicating that HPL-supplemented ex vivo culturing media support $\mathrm{T}$ cells to preserve their less differentiated cell phenotype resulting in their longstanding antitumor activity and persistence (191). Above all this, some researchers have demonstrated that treatment of mouse $\mathrm{CD}^{+} \mathrm{T}$ cells with the $\mathrm{S}$ enantiomer of the 2-hydroxyglutarate (S-2HG) in ex vivo culture significantly enhances their in vivo expansion, persistence, and tumoricidal activity (192). Recently, the same group has indicated that S-2HG acts as an immune metabolite and helps clinical-grade allogeneic CAR-Ts maintain their central memory phenotype and exhibit enhanced antitumor activity (193).

\subsubsection{Ex Vivo Culture Duration}

According to the relationship between the state of $\mathrm{T}$-cell differentiation and the potential for in vivo engraftment and persistence, some researchers have proposed that reducing the duration of ex vivo culturing can limit differentiation and significant loss of stemness and enhance the efficacy of CAR-T therapy (194). Ghassemi et al. have demonstrated that reduced culturing duration helps CAR-Ts have improved ex vivo expansion and effector function which are directly correlated with enhanced in vivo engraftment and tumoricidal activity (194). These researchers also demonstrated that these CAR-Ts eradicated human B-ALL in a murine xenograft model even at a 6-fold lower dose as compared with their counterparts expanded with the conventional ex vivo durations (194). In a nutshell, Ghassemi et al. demonstrated that the antileukemic activity of CAR-Ts is inversely correlated with their ex vivo culturing duration (194).

\subsubsection{Other Factors}

Upon activation, $\mathrm{T}$ cells steer their metabolism from fatty acid oxidation to glycolysis which helps them keep their effector function (195). It has been found that $\mathrm{T}$ cells with a memorylike phenotype have a low level of glucose uptake in comparison with T cells with an effector-like phenotype (195). Sukumar et al. have demonstrated that activating $\mathrm{CD} 8^{+} \mathrm{T}$ cells in the presence of 2-deoxyglucose, which is a glycolysis pathway suppressor, can result in the formation of memory T cells (195). Moreover, other researchers have shown that pharmacologic inhibition of the serine/threonine kinase Akt promotes the expansion of TILs with transcriptional, metabolic, and functional features of memory $\mathrm{T}$ cells (196). Furthermore, Urak et al. also highlighted the Akt pathway involvement in T-cell differentiation state and memory phenotype formation (197). They demonstrated that the inhibition of Akt using an Akt inhibitor during ex vivo expansion of CAR-Ts leads to the production of CAR-Ts expressing higher levels of CD62L and CD28 as compared with CAR-Ts generated without Akt inhibition (197). Moreover, these researchers reported that ex vivo Akt-inhibited CAR-Ts exhibit superior antitumor functionality both in vivo and in vitro as compared with conventional CAR-Ts (197). 
Lately, it has been found that the differentiation fate of $\mathrm{CD} 8^{+} \mathrm{T}$ cells is regulated by the methylcytosine dioxygenase ten-eleven translocation 2 (TET2) $(198,199)$. TET2 loss results in the formation of memory-like phenotype in $\mathrm{CD}^{+} \mathrm{T}$ cells without any impairment of their expansion or effector function $(198,199)$. Moreover, TET2-disrupted CAR-Ts have exhibited central memory phenotype at the expansion peak, which highlights the beneficial impact of TET2 suppression in CAR-Ts $(198,199)$. Furthermore, Kondo et al. have demonstrated that activated effector $\mathrm{T}$ cells can be converted into $\mathrm{T}_{\mathrm{SCM}^{-}}$-like ( $\mathrm{i}_{\mathrm{SCM}}$ ) cells by co-culturing with OP9 stromal cells expressing a Notch ligand such as Delta-like 1 (200-202). It has been found that using IL-7 and IL15 can significantly be beneficial for the production of $\mathrm{iT}_{\mathrm{SCM}}$ cells (201). These researchers also indicated that $\mathrm{iT}_{\mathrm{SCM}}$ cells are tolerance-resistant alongside exhibiting robust engraftment, persistence, and tumoricidal activity in vivo (202). More recently, Kondo et al. reported that conventional human CAR-Ts can also be converted into $\mathrm{iT}_{\mathrm{SCM}}$ CAR-Ts via Notch signaling-mediated mitochondrial metabolic reprogramming (203). Additionally, they found that Forkhead box M1 (FOXM1) is involved in the downstream signaling of the Notch pathway (203). FOXM1 is mainly responsible for the metabolic reprogramming of $\mathrm{T}$ cells and stem cell memory phenotype induction, and $\mathrm{iT}_{\mathrm{SCM}}$ CAR-Ts generated using FOXM1 induction are as functional as $\mathrm{iT}_{\mathrm{SCM}} \mathrm{CAR}-$ Ts generated using Notch induction (203). In addition to the mentioned strategies, it is known that the $4-1 \mathrm{BB}$ signaling promotes $\mathrm{T}$-cell central memory phenotype formation and preservation in CAR-Ts by promoting oxidative metabolism (204). Therefore, using the 4-1BB co-stimulatory domain in the construct of CAR-Ts helps preserve their central memory phenotype and in vivo expansion capacity (46).

\section{CONCLUSION}

CAR-T therapy will just be another unfulfilled promise without optimized efficacy and efficient toxicity management strategies.
This type of therapy offers a new fighting tool with improved targeting capacity capable of fighting R/R B-ALL with durable outcomes (12-20). As outlined in this review, the unfavorable adverse events of B-ALL CAR-T therapy appear as the leading obstacle in the way of its broader therapeutic benefit; therefore, an ideal balance between safety and efficacy is critically required (59). Rapidly evolving research advances in genomic editing methods alongside a better understanding of the mechanisms underlying the discussed toxicities will help us further prevent or manage CRS and neurotoxicity. Moving forward, having a combination of different strategies or an all-in-one unified approach for producing off-the-shelf allogeneic CAR-Ts can decrease the duration of CAR-T production and delivery and eliminate other limitations regarding the generation of autologous CAR-Ts using T cells isolated from heavily treated R/R B-ALL patients (205). A magnificent deal of effort has now been dedicated to these strategies since they can be beneficial for CAR-T therapy in both hematologic malignancies and solid tumors. However, some of these strategies are still in their infancy, as others have been evaluated in preclinical and clinical studies. Furthermore, other aspects of CAR-T therapy can also be improved for having a better CAR-T persistence and antitumor activity by controlling the factors that affect the phenotype of the final T-cell product. Despite all this, the financial limitations and disease relapse mechanisms can still be named as other limitations of B-ALL CAR-T therapy requiring counterstrategies.

\section{AUTHOR CONTRIBUTIONS}

PouS: Conceptualization, Investigation, Writing - original draft, Writing - review \& editing, Validation, Supervision. PooS: Conceptualization, Investigation, Writing - original draft, Writing - review \& editing, Validation, Supervision. FR: Writing - review \& editing, Validation. All authors contributed to the article and approved the submitted version.

\section{REFERENCES}

1. Huang FL, Liao EC, Li CL, Yen CY, Yu SJ. Pathogenesis of Pediatric B-Cell Acute Lymphoblastic Leukemia: Molecular Pathways and Disease Treatments. Oncol Lett (2020) 20:448-54. doi: 10.3892/ol.2020.11583

2. Siegel RL, Miller KD, Fuchs HE, Jemal A. Cancer Statistics, 2021. CA: Cancer J Clin (2021) 71:7-33. doi: 10.3322/caac.21654

3. Ward E, DeSantis C, Robbins A, Kohler B, Jemal A. Childhood and Adolescent Cancer Statistics, 2014. CA: Cancer J Clin (2014) 64:83-103. doi: 10.3322/caac. 21219

4. Hunger SP, Lu X, Devidas M, Camitta BM, Gaynon PS, Winick NJ, et al. Improved Survival for Children and Adolescents With Acute Lymphoblastic Leukemia Between 1990 and 2005: A Report From the Children's Oncology Group. J Clin Oncol: Off J Am Soc Clin Oncol (2012) 30:1663-9. doi: 10.1200/ jco.2011.37.8018

5. Saini N, Marin D, Ledesma C, Delgado R, Rondon G, Popat UR, et al. Impact of TKIs Post-Allogeneic Hematopoietic Cell Transplantation in Philadelphia Chromosome-Positive ALL. Blood (2020) 136:1786-9. doi: 10.1182/blood.2019004685

6. Malard F, Mohty M. Acute Lymphoblastic Leukaemia. Lancet (London England) (2020) 395:1146-62. doi: 10.1016/s0140-6736(19)33018-1

7. Paul S, Rausch CR, Nasnas PE, Kantarjian H, Jabbour EJ. Treatment of Relapsed/Refractory Acute Lymphoblastic Leukemia. Clin Adv Hematol Oncol: $H \hookleftarrow O$ (2019) 17:166-75.

8. Ko RH, Ji L, Barnette P, Bostrom B, Hutchinson R, Raetz E, et al. Outcome of Patients Treated for Relapsed or Refractory Acute Lymphoblastic Leukemia: A Therapeutic Advances in Childhood Leukemia Consortium Study. J Clin Oncol: Off J Am Soc Clin Oncol (2010) 28:648-54. doi: 10.1200/ jco.2009.22.2950

9. Sun W, Malvar J, Sposto R, Verma A, Wilkes JJ, Dennis R, et al. Outcome of Children With Multiply Relapsed B-Cell Acute Lymphoblastic Leukemia: A Therapeutic Advances in Childhood Leukemia \& Lymphoma Study. Leukemia (2018) 32:2316-25. doi: 10.1038/s41375-018-0094-0

10. Dobosz P, Dzieciatkowski T. The Intriguing History of Cancer Immunotherapy. Front Immunol (2019) 10:2965. doi: 10.3389/fimmu.2019.02965

11. Safarzadeh Kozani P, Safarzadeh Kozani P, Rahbarizadeh F. CAR-T Cell Therapy in T-Cell Malignancies: Is Success a Low-Hanging Fruit? Stem Cell Reseach Ther (2021) 12:527. doi: 10.1186/s13287-021-02595-0 
12. Gardner RA, Finney O, Annesley C, Brakke H, Summers C, Leger K, et al. Intent-To-Treat Leukemia Remission by CD19 CAR T Cells of Defined Formulation and Dose in Children and Young Adults. Blood (2017) 129:3322-31. doi: 10.1182/blood-2017-02-769208

13. Lee DW, Kochenderfer JN, Stetler-Stevenson M, Cui YK, Delbrook C, Feldman SA, et al. T Cells Expressing CD19 Chimeric Antigen Receptors for Acute Lymphoblastic Leukaemia in Children and Young Adults: A Phase 1 Dose-Escalation Trial. Lancet (London England) (2015) 385:517-28. doi: 10.1016/s0140-6736(14)61403-3

14. Maude SL, Frey N, Shaw PA, Aplenc R, Barrett DM, Bunin NJ, et al. Chimeric Antigen Receptor T Cells for Sustained Remissions in Leukemia. New Engl J Med (2014) 371:1507-17. doi: 10.1056/NEJMoa1407222

15. Maude SL, Laetsch TW, Buechner J, Rives S, Boyer M, Bittencourt H, et al. Tisagenlecleucel in Children and Young Adults With B-Cell Lymphoblastic Leukemia. N Engl J Med (2018) 378:439-48. doi: 10.1056/ NEJMoa1709866

16. Park JH, Rivière I, Gonen $\mathrm{M}$, Wang X, Sénéchal B, Curran KJ, et al. LongTerm Follow-Up of CD19 CAR Therapy in Acute Lymphoblastic Leukemia. N Engl J Med (2018) 378:449-59. doi: 10.1056/NEJMoa1709919

17. Turtle CJ, Hanafi LA, Berger C, Gooley TA, Cherian S, Hudecek M, et al. CD19 CAR-T Cells of Defined CD4+:CD8+ Composition in Adult B Cell ALL Patients. J Clin Invest (2016) 126:2123-38. doi: 10.1172/jci85309

18. Eshhar Z, Waks T, Gross G, Schindler DG. Specific Activation and Targeting of Cytotoxic Lymphocytes Through Chimeric Single Chains Consisting of Antibody-Binding Domains and the Gamma or Zeta Subunits of the Immunoglobulin and T-Cell Receptors. Proc Natl Acad Sci USA (1993) 90:720-4. doi: 10.1073/pnas.90.2.720

19. Frey NV. Chimeric Antigen Receptor T Cells for Acute Lymphoblastic Leukemia. Am J Hematol (2019) 94:S24-s7. doi: 10.1002/ajh.25442

20. Safarzadeh Kozani P, Safarzadeh Kozani P, O'Connor RS. In Like a Lamb; Out Like a Lion: Marching CAR T Cells Toward Enhanced Efficacy in BALL. Mol Cancer Ther (2021) 20:1223-33. doi: 10.1158/1535-7163.mct-201089

21. Safarzadeh Kozani P, Safarzadeh Kozani P, Rahbarizadeh F, Khoshtinat Nikkhoi S. Strategies for Dodging the Obstacles in CAR T Cell Therapy. Front Oncol (2021) 11:627549. doi: 10.3389/fonc.2021.627549

22. Hashem Boroojerdi M, Rahbarizadeh F, Safarzadeh Kozani P, Kamali E, Safarzadeh Kozani P. Strategies for Having a More Effective and Less Toxic CAR T-Cell Therapy for Acute Lymphoblastic Leukemia. Med Oncol (2020) 37:100. doi: 10.1007/s12032-020-01416-3

23. Safarzadeh Kozani P, Safarzadeh Kozani P, Rahbarizadeh F. Novel Antigens of CAR T Cell Therapy: New Roads; Old Destination. Trans Oncol (2021) 14:101079. doi: 10.1016/j.tranon.2021.101079

24. Summers C, Annesley C, Bleakley M, Dahlberg A, Jensen MC, Gardner R. Long Term Follow-Up After SCRI-CAR19v1 Reveals Late Recurrences As Well As a Survival Advantage to Consolidation With HCT After CAR T Cell Induced Remission. Blood (2018) 132:967. doi: 10.1182/blood-2018-99115599

25. Santomasso BD, Park JH, Salloum D, Riviere I, Flynn J, Mead E, et al. Clinical and Biological Correlates of Neurotoxicity Associated With CAR TCell Therapy in Patients With B-Cell Acute Lymphoblastic Leukemia. Cancer Discov (2018) 8:958-71. doi: 10.1158/2159-8290.cd-17-1319

26. Gust J, Hay KA, Hanafi LA, Li D, Myerson D, Gonzalez-Cuyar LF, et al. Endothelial Activation and Blood-Brain Barrier Disruption in Neurotoxicity After Adoptive Immunotherapy With CD19 CAR-T Cells. Cancer Discov (2017) 7:1404-19. doi: 10.1158/2159-8290.Cd-17-0698

27. Porter D, Frey N, Wood PA, Weng Y, Grupp SA. Grading of Cytokine Release Syndrome Associated With the CAR T Cell Therapy Tisagenlecleucel. J Hematol Oncol (2018) 11:35. doi: 10.1186/s13045-0180571-y

28. Shimabukuro-Vornhagen A, Gödel P, Subklewe M, Stemmler HJ, Schlößer HA, Schlaak M, et al. Cytokine Release Syndrome. J Immunother Cancer (2018) 6:56. doi: 10.1186/s40425-018-0343-9

29. Arnold DE, Maude SL, Callahan CA, DiNofia AM, Grupp SA, Heimall JR. Subcutaneous Immunoglobulin Replacement Following CD19-Specific Chimeric Antigen Receptor T-Cell Therapy for B-Cell Acute Lymphoblastic Leukemia in Pediatric Patients. Pediatr Blood Cancer (2020) 67:e28092. doi: 10.1002/pbc.28092
30. Yang Y, Jacoby E, Fry TJ. Challenges and Opportunities of Allogeneic Donor-Derived CAR T Cells. Curr Opin Hematol (2015) 22:509-15. doi: 10.1097/moh.0000000000000181

31. Sanber K, Savani B, Jain T. Graft-Versus-Host Disease Risk After Chimeric Antigen Receptor T-Cell Therapy: The Diametric Opposition of T Cells. Br J Haematol (2021). doi: 10.1111/bjh.17544

32. Prasad V. Tisagenlecleucel-The First Approved CAR-T-Cell Therapy: Implications for Payers and Policy Makers. Nat Rev Clin Oncol (2018) 15:11-2. doi: 10.1038/nrclinonc.2017.156

33. Bouchkouj N, Kasamon YL, de Claro RA, George B, Lin X, Lee S, et al. FDA Approval Summary: Axicabtagene Ciloleucel for Relapsed or Refractory Large B-Cell Lymphoma. Clin Cancer Res (2019) 25:1702-8. doi: 10.1158/ 1078-0432.CCR-18-2743

34. Mullard A. FDA Approves First BCMA-Targeted CAR-T Cell Therapy. Nat Rev Drug Discovery (2021) 20:332. doi: 10.1038/d41573-021-00063-1

35. Voelker R. CAR-T Therapy Is Approved for Mantle Cell Lymphoma. Jama (2020) 324:832. doi: 10.1001/jama.2020.15456

36. Mullard A. FDA Approves First CAR T Therapy. Nat Rev Drug Discov (2017) 16:669. doi: 10.1038/nrd.2017.196

37. Mullard A. FDA Approves Fourth CAR-T Cell Therapy. Nat Rev Drug Discov (2021) 20:166. doi: 10.1038/d41573-021-00031-9

38. FDA Approves Second CAR T-Cell Therapy. Cancer Discovery (2018) 8:5-6. doi: 10.1158/2159-8290.Cd-nb2017-155

39. Mian A, Hill BT. Brexucabtagene Autoleucel for the Treatment of Relapsed/ Refractory Mantle Cell Lymphoma. Expert Opin Biol Ther (2021) 21:435-41. doi: 10.1080/14712598.2021.1889510

40. Stoiber S, Cadilha BL, Benmebarek MR, Lesch S, Endres S, Kobold S. Limitations in the Design of Chimeric Antigen Receptors for Cancer Therapy. Cells (2019) 8:472. doi: 10.3390/cells8050472

41. Zhao L, Cao YJ. Engineered T Cell Therapy for Cancer in the Clinic. Front Immunol (2019) 10:2250. doi: 10.3389/fimmu.2019.02250

42. Li W, Qiu S, Chen J, Jiang S, Chen W, Jiang J, et al. Chimeric Antigen Receptor Designed to Prevent Ubiquitination and Downregulation Showed Durable Antitumor Efficacy. Immunity (2020) 53:456-70.e6. doi: 10.1016/ j.immuni.2020.07.011

43. Collinson-Pautz MR, Chang WC, Lu A, Khalil M, Crisostomo JW, Lin PY, et al. Constitutively Active MyD88/CD40 Costimulation Enhances Expansion and Efficacy of Chimeric Antigen Receptor T Cells Targeting Hematological Malignancies. Leukemia (2019) 33:2195-207. doi: 10.1038/ s41375-019-0417-9

44. Wang E, Wang LC, Tsai CY, Bhoj V, Gershenson Z, Moon E, et al. Generation of Potent T-Cell Immunotherapy for Cancer Using DAP12Based, Multichain, Chimeric Immunoreceptors. Cancer Immunol Res (2015) 3:815-26. doi: 10.1158/2326-6066.Cir-15-0054

45. Guedan S, Madar A, Casado-Medrano V, Shaw C, Wing A, Liu F, et al. Single Residue in CD28-Costimulated CAR-T Cells Limits Long-Term Persistence and Antitumor Durability. J Clin Invest (2020) 130:3087-97. doi: $10.1172 /$ jci133215

46. Drent E, Poels R, Ruiter R, van de Donk N, Zweegman S, Yuan H, et al. Combined CD28 and 4-1BB Costimulation Potentiates Affinity-Tuned Chimeric Antigen Receptor-Engineered T Cells. Clin Cancer Res (2019) 25:4014-25. doi: 10.1158/1078-0432.Ccr-18-2559

47. Chapman NM, Gottschalk S, Chi H. Preventing Ubiquitination Improves CAR T Cell Therapy via 'CAR Merry-Go-Around'. Immunity (2020) 53:243-5. doi: 10.1016/j.immuni.2020.07.023

48. Caratelli S, Sconocchia T, Arriga R, Coppola A, Lanzilli G, Lauro D, et al. Fc $\gamma$ Chimeric Receptor-Engineered T Cells: Methodology, Advantages, Limitations, and Clinical Relevance. Front Immunol (2017) 8:457. doi: 10.3389/fimmu.2017.00457

49. Karlsson H, Svensson E, Gigg C, Jarvius M, Olsson-Strömberg U, Savoldo B, et al. Evaluation of Intracellular Signaling Downstream Chimeric Antigen Receptors. PloS One (2015) 10:e0144787. doi: 10.1371/journal.pone.0144787

50. Ng YY, Tay JCK, Li Z, Wang J, Zhu J, Wang S. T Cells Expressing NKG2D CAR With a DAP12 Signaling Domain Stimulate Lower Cytokine Production While Effective in Tumor Eradication. Mol Ther (2020) 29:7585. doi: 10.1016/j.ymthe.2020.08.016

51. Duell J, Lurati S, Dittrich M, Bedke T, Pule M, Einsele H, et al. First Generation Chimeric Antigen Receptor Display Functional Defects In Key 
Signal Pathways Upon Antigen Stimulation. Blood (2010) 116:2088-. doi: 10.1182/blood.V116.21.2088.2088

52. van der Stegen SJ, Hamieh M, Sadelain M. The Pharmacology of SecondGeneration Chimeric Antigen Receptors. Nat Rev Drug Discov (2015) 14:499-509. doi: 10.1038/nrd4597

53. Zhong XS, Matsushita M, Plotkin J, Riviere I, Sadelain M. Chimeric Antigen Receptors Combining 4-1BB and CD28 Signaling Domains Augment PI3kinase/AKT/Bcl-XL Activation and CD8+ T Cell-Mediated Tumor Eradication. Mol Ther (2010) 18:413-20. doi: 10.1038/mt.2009.210

54. Chmielewski M, Abken H. TRUCKs: The Fourth Generation of CARs. Expert Opin Biol Ther (2015) 15:1145-54. doi: 10.1517/14712598.2015.1046430

55. Tokarew N, Ogonek J, Endres S, von Bergwelt-Baildon M, Kobold S. Teaching an Old Dog New Tricks: Next-Generation CAR T Cells. Br J Cancer (2019) 120:26-37. doi: 10.1038/s41416-018-0325-1

56. Yeku OO, Brentjens RJ. Armored CAR T-Cells: Utilizing Cytokines and ProInflammatory Ligands to Enhance CAR T-Cell Anti-Tumour Efficacy. Biochem Soc Trans (2016) 44:412-8. doi: 10.1042/bst20150291

57. Shalabi H, Sachdev V, Kulshreshtha A, Cohen JW, Yates B, Rosing DR, et al. Impact of Cytokine Release Syndrome on Cardiac Function Following CD19 CAR-T Cell Therapy in Children and Young Adults With Hematological Malignancies. J Immunother Cancer (2020) 8:e001159. doi: 10.1136/jitc2020-001159

58. Dixon BN, Daley RJ, Buie LW, Hsu M, Park JH, Brentjens RJ, et al. Correlation of IL-6 Secretion and Hyponatremia With the Use of CD19+ Chimeric Antigen Receptor T-Cells. Clin Nephrol (2020) 93:42-6. doi: $10.5414 / \mathrm{cn} 109872$

59. Ishii K, Pouzolles M, Chien CD, Erwin-Cohen RA, Kohler ME, Qin H, et al. Perforin-Deficient CAR T Cells Recapitulate Late-Onset Inflammatory Toxicities Observed in Patients. J Clin Invest (2020) 130:5425-43. doi: $10.1172 /$ jci130059

60. Ghosh Arjun K, Chen Daniel H, Guha A, Mackenzie S, Walker JM, Roddie C. CAR T Cell Therapy-Related Cardiovascular Outcomes and Management. JACC: Cardio Oncol (2020) 2:97-109. doi: 10.1016/ j.jaccao.2020.02.011

61. Taraseviciute A, Tkachev V, Ponce R, Turtle CJ, Snyder JM, Liggitt HD, et al. Chimeric Antigen Receptor T Cell-Mediated Neurotoxicity in Nonhuman Primates. Cancer Discov (2018) 8:750-63. doi: 10.1158/2159-8290.Cd-171368

62. Gust J, Taraseviciute A, Turtle CJ. Neurotoxicity Associated With CD19Targeted CAR-T Cell Therapies. CNS Drugs (2018) 32:1091-101. doi: 10.1007/s40263-018-0582-9

63. Neelapu SS. Managing the Toxicities of CAR T-Cell Therapy. Hematol Oncol (2019) 37 Suppl 1:48-52. doi: 10.1002/hon.2595

64. Parker KR, Migliorini D, Perkey E, Yost KE, Bhaduri A, Bagga P, et al. Single-Cell Analyses Identify Brain Mural Cells Expressing CD19 as Potential Off-Tumor Targets for CAR-T Immunotherapies. Cell (2020) 183:126-42.e17. doi: 10.1016/j.cell.2020.08.022

65. Spear P, Wu MR, Sentman ML, Sentman CL. NKG2D Ligands as Therapeutic Targets. Cancer Immun (2013) 13:8.

66. Giavridis T, van der Stegen SJC, Eyquem J, Hamieh M, Piersigilli A, Sadelain M. CAR T Cell-Induced Cytokine Release Syndrome is Mediated by Macrophages and Abated by IL-1 Blockade. Nat Med (2018) 24:731-8. doi: 10.1038/s41591-018-0041-7

67. Norelli M, Camisa B, Barbiera G, Falcone L, Purevdorj A, Genua M, et al. Monocyte-Derived IL-1 and IL-6 are Differentially Required for CytokineRelease Syndrome and Neurotoxicity Due to CAR T Cells. Nat Med (2018) 24:739-48. doi: 10.1038/s41591-018-0036-4

68. Hay KA. Cytokine Release Syndrome and Neurotoxicity After CD19 Chimeric Antigen Receptor-Modified (CAR-) T Cell Therapy. Br J Haematol (2018) 183:364-74. doi: 10.1111/bjh.15644

69. Kang L, Tang X, Zhang J, Li M, Xu N, Qi W, et al. Interleukin-6-Knockdown of Chimeric Antigen Receptor-Modified T Cells Significantly Reduces IL-6 Release From Monocytes. Exp Hematol Oncol (2020) 9:11. doi: 10.1186/ s40164-020-00166-2

70. Liu ZF, Chen LY, Wang J, Kang LQ, Tang H, Zhou Y, et al. Successful Treatment of Acute B Lymphoblastic Leukemia Relapse in the Skin and Testicle by Anti-CD19 CAR-T With IL-6 Knocking Down: A Case Report. Biomark Res (2020) 8:12. doi: 10.1186/s40364-020-00193-5
71. Chen LY, Kang LQ, Zhou HX, Gao HQ, Zhu XF, Xu N, et al. Successful Application of Anti-CD19 CAR-T Therapy With IL-6 Knocking Down to Patients With Central Nervous System B-Cell Acute Lymphocytic Leukemia. Transl Oncol (2020) 13:100838. doi: 10.1016/j.tranon.2020.100838

72. Neelapu SS, Tummala S, Kebriaei P, Wierda W, Gutierrez C, Locke FL, et al. Chimeric Antigen Receptor T-Cell Therapy - Assessment and Management of Toxicities. Nat Rev Clin Oncol (2018) 15:47-62. doi: 10.1038/ nrclinonc.2017.148

73. Liu S, Deng B, Yin Z, Pan J, Lin Y, Ling Z, et al. Corticosteroids do Not Influence the Efficacy and Kinetics of CAR-T Cells for B-Cell Acute Lymphoblastic Leukemia. Blood Cancer J (2020) 10:15. doi: 10.1038/ s41408-020-0280-y

74. Kakutani M, Takeuchi K, Waga I, Iwamura H, Wakitani K. JTE-607, a Novel Inflammatory Cytokine Synthesis Inhibitor Without Immunosuppression, Protects From Endotoxin Shock in Mice. Inflamm Res (1999) 48:461-8. doi: 10.1007/s000110050487

75. Tajima N, Fukui K, Uesato N, Maruhashi J, Yoshida T, Watanabe Y, et al. JTE-607, a Multiple Cytokine Production Inhibitor, Induces Apoptosis Accompanied by an Increase in P21waf1/Cip1 in Acute Myelogenous Leukemia Cells. Cancer Sci (2010) 101:774-81. doi: 10.1111/j.13497006.2009.01446.x

76. Borozdenkova S, Mant TG, Allen E, Pu K, Hoshino S, Jurcevic S. Effects of a Cytokine Inhibitor, JTE-607, on the Response to Endotoxin in Healthy Human Volunteers. Int Immunopharmacol (2011) 11:1837-43. doi: 10.1016/ j.intimp.2011.07.013

77. Kakegawa J, Sakane N, Suzuki K, Yoshida T. JTE-607, a Multiple Cytokine Production Inhibitor, Targets CPSF3 and Inhibits pre-mRNA Processing. Biochem Biophys Res Commun (2019) 518:32-7. doi: 10.1016/ j.bbrc.2019.08.004

78. Futami M, Suzuki K, Kato S, Ohmae S, Tahara Y, Nojima M, et al. The Novel Multi-Cytokine Inhibitor TO-207 Specifically Inhibits Pro-Inflammatory Cytokine Secretion in Monocytes Without Affecting the Killing Ability of CAR T Cells. PloS One (2020) 15:e0231896. doi: 10.1371/ journal.pone. 0231896

79. Sterner RM, Sakemura R, Cox MJ, Yang N, Khadka RH, Forsman CL, et al. GM-CSF Inhibition Reduces Cytokine Release Syndrome and Neuroinflammation But Enhances CAR-T Cell Function in Xenografts. Blood (2019) 133:697-709. doi: 10.1182/blood-2018-10-881722

80. Neelapu SS, Locke FL, Bartlett NL, Lekakis LJ, Miklos DB, Jacobson CA, et al. Axicabtagene Ciloleucel CAR T-Cell Therapy in Refractory Large BCell Lymphoma. N Engl J Med (2017) 377:2531-44. doi: 10.1056/ NEJMoa1707447

81. Teachey DT, Lacey SF, Shaw PA, Melenhorst JJ, Maude SL, Frey N, et al. Identification of Predictive Biomarkers for Cytokine Release Syndrome After Chimeric Antigen Receptor T-Cell Therapy for Acute Lymphoblastic Leukemia. Cancer Discov (2016) 6:664-79. doi: 10.1158/2159-8290.Cd-16-0040

82. Park JH, Romero FA, Taur Y, Sadelain M, Brentjens RJ, Hohl TM, et al. Cytokine Release Syndrome Grade as a Predictive Marker for Infections in Patients With Relapsed or Refractory B-Cell Acute Lymphoblastic Leukemia Treated With Chimeric Antigen Receptor T Cells. Clin Infect Dis (2018) 67:533-40. doi: 10.1093/cid/ciy152

83. Russo RC, Garcia CC, Teixeira MM, Amaral FA. The CXCL8/IL-8 Chemokine Family and its Receptors in Inflammatory Diseases. Expert Rev Clin Immunol (2014) 10:593-619. doi: 10.1586/1744666x.2014.894886

84. Deshmane SL, Kremlev S, Amini S, Sawaya BE. Monocyte Chemoattractant Protein-1 (MCP-1): An Overview. J Interferon Cytokine Res (2009) 29:31326. doi: 10.1089/jir.2008.0027

85. Sachdeva M, Duchateau P, Depil S, Poirot L, Valton J. GranulocyteMacrophage Colony-Stimulating Factor Inactivation in CAR T-Cells Prevents Monocyte-Dependent Release of Key Cytokine Release Syndrome Mediators. J Biol Chem (2019) 294:5430-7. doi: 10.1074/jbc.AC119.007558

86. Johnson JD, Campisi J, Sharkey CM, Kennedy SL, Nickerson M, Greenwood BN, et al. Catecholamines Mediate Stress-Induced Increases in Peripheral and Central Inflammatory Cytokines. Neuroscience (2005) 135:1295-307. doi: 10.1016/j.neuroscience.2005.06.090

87. Flierl MA, Rittirsch D, Nadeau BA, Chen AJ, Sarma JV, Zetoune FS, et al. Phagocyte-Derived Catecholamines Enhance Acute Inflammatory Injury. Nature (2007) 449:721-5. doi: 10.1038/nature06185 
88. Flierl MA, Rittirsch D, Nadeau BA, Sarma JV, Day DE, Lentsch AB, et al. Upregulation of Phagocyte-Derived Catecholamines Augments the Acute Inflammatory Response. PloS One (2009) 4:e4414. doi: 10.1371/ journal.pone.0004414

89. Shaked I, Hanna RN, Shaked H, Chodaczek G, Nowyhed HN, Tweet G, et al. Transcription Factor Nr4a1 Couples Sympathetic and Inflammatory Cues in CNS-Recruited Macrophages to Limit Neuroinflammation. Nat Immunol (2015) 16:1228-34. doi: 10.1038/ni.3321

90. Staedtke V, Bai RY, Kim K, Darvas M, Davila ML, Riggins GJ, et al. Disruption of a Self-Amplifying Catecholamine Loop Reduces Cytokine Release Syndrome. Nature (2018) 564:273-7. doi: 10.1038/s41586-018-0774-y

91. Vollmar AM. The Role of Atrial Natriuretic Peptide in the Immune System. Peptides (2005) 26:1086-94. doi: 10.1016/j.peptides.2004.08.034

92. Wang W, Tang J, Wei F. Updated Understanding of the Outbreak of 2019 Novel Coronavirus (2019-Ncov) in Wuhan, China. J Med Virol (2020) 92:441-7. doi: 10.1002/jmv.25689

93. Gong X, Darpo B, Xue H, Punwani N, He K, Barbour AM, et al. Evaluation of Clinical Cardiac Safety of Itacitinib, a JAK1 Inhibitor, in Healthy Participants. Clin Pharmacol Drug Dev (2020) 9:677-88. doi: 10.1002/ cpdd.758

94. Huarte E, O'Connor RS, Parker M, Huang T, Milone MC, Smith P. Prophylactic Itacitinib (INCB039110) for the Prevention of Cytokine Release Syndrome Induced By Chimeric Antigen Receptor T-Cells (CART-Cells) Therapy. Blood (2019) 134:1934-. doi: 10.1182/blood-2019-128288

95. Phillips TJ, Forero-Torres A, Sher T, Diefenbach CS, Johnston P, Talpaz M, et al. Phase 1 Study of the PI3K $\delta$ Inhibitor INCB040093 \pm JAK1 Inhibitor Itacitinib in Relapsed/Refractory B-Cell Lymphoma. Blood (2018) 132:293306. doi: 10.1182/blood-2017-10-812701

96. Forero-Torres A, Ramchandren R, Yacoub A, Wertheim MS, Edenfield WJ, Caimi P, et al. Parsaclisib, a Potent and Highly Selective PI3K $\delta$ Inhibitor, in Patients With Relapsed or Refractory B-Cell Malignancies. Blood (2019) 133:1742-52. doi: 10.1182/blood-2018-08-867499

97. Covington M, He X, Scuron M, Li J, Collins R, Juvekar A, et al. Preclinical Characterization of Itacitinib (INCB039110), a Novel Selective Inhibitor of JAK1, for the Treatment of Inflammatory Diseases. Eur J Pharmacol (2020) 885:173505. doi: 10.1016/j.ejphar.2020.173505

98. Angelini J, Talotta R, Roncato R, Fornasier G, Barbiero G, Dal Cin L, et al. JAK-Inhibitors for the Treatment of Rheumatoid Arthritis: A Focus on the Present and an Outlook on the Future. Biomolecules (2020) 10:1002. doi: 10.3390/biom10071002

99. Schroeder MA, Khoury HJ, Jagasia M, Ali H, Schiller GJ, Staser K, et al. A Phase 1 Trial of Itacitinib, a Selective JAK1 Inhibitor, in Patients With Acute Graft-Versus-Host Disease. Blood Adv (2020) 4:1656-69. doi: 10.1182/ bloodadvances.2019001043

100. Shah NN, Johnson BD, Fenske TS, Raj RV, Hari P. Intrathecal Chemotherapy for Management of Steroid-Refractory CAR T-CellAssociated Neurotoxicity Syndrome. Blood Adv (2020) 4:2119-22. doi: 10.1182/bloodadvances.2020001626

101. Yucebay F, Maakaron J, Grana A, Jaglowski S, Roddy J. Intrathecal Chemotherapy: An Alternative Treatment Strategy to Prolonged Corticosteroids for Severe CAR T Associated Neurotoxicity. Biol Blood Marrow Transplant (2020) 26:S312. doi: 10.1016/j.bbmt.2019.12.390

102. Danylesko I, Chowers G, Shouval R, Besser MJ, Jacoby E, Shimoni A, et al. Treatment With Anti CD19 Chimeric Antigen Receptor T Cells After Antibody-Based Immunotherapy in Adults With Acute Lymphoblastic Leukemia. Curr Res Trans Med (2020) 68:17-22. doi: 10.1016/ j.retram.2019.12.001

103. Kantarjian H, Stein A, Gökbuget N, Fielding AK, Schuh AC, Ribera JM, et al. Blinatumomab Versus Chemotherapy for Advanced Acute Lymphoblastic Leukemia. N Engl J Med (2017) 376:836-47. doi: 10.1056/NEJMoa1609783

104. Kantarjian HM, DeAngelo DJ, Stelljes M, Martinelli G, Liedtke M, Stock W, et al. Inotuzumab Ozogamicin Versus Standard Therapy for Acute Lymphoblastic Leukemia. N Engl J Med (2016) 375:740-53. doi: 10.1056/ NEJMoa 1509277

105. Xiao X, He X, Li Q, Zhang H, Meng J, Jiang Y, et al. Plasma Exchange Can Be an Alternative Therapeutic Modality for Severe Cytokine Release Syndrome After Chimeric Antigen Receptor-T Cell Infusion: A Case Report. Clin Cancer Res (2019) 25:29-34. doi: 10.1158/1078-0432.Ccr-18-1379
106. Jin X, Cao Y, Wang L, Sun R, Cheng L, He X, et al. HLA-Matched and HLAHaploidentical Allogeneic CD19-Directed Chimeric Antigen Receptor TCell Infusions are Feasible in Relapsed or Refractory B-Cell Acute Lymphoblastic Leukemia Before Hematopoietic Stem Cell Transplantation. Leukemia (2020) 34:909-13. doi: 10.1038/s41375-019-0610-x

107. Stoner A, Miller JO, Flatt T, Wallisch JS. Extracorporeal Membrane Oxygenation as a Bridge to Chimeric Antigen Receptor T-Cell Therapy for Severe Refractory Sepsis in the Setting of Relapsed Refractory Pediatric Acute Lymphoblastic Leukemia: A Case Report. Crit Care Explor (2020) 2: e0093. doi: 10.1097/cce.0000000000000093

108. Heng G, Jia J, Li S, Fu G, Wang M, Qin D, et al. Sustained Therapeutic Efficacy of Humanized Anti-CD19 Chimeric Antigen Receptor T Cells in Relapsed/Refractory Acute Lymphoblastic Leukemia. Clin Cancer Res (2020) 26:1606-15. doi: 10.1158/1078-0432.Ccr-19-1339

109. Hay KA, Hanafi LA, Li D, Gust J, Liles WC, Wurfel MM, et al. Kinetics and Biomarkers of Severe Cytokine Release Syndrome After CD19 Chimeric Antigen Receptor-Modified T-Cell Therapy. Blood (2017) 130:2295-306. doi: 10.1182/blood-2017-06-793141

110. Liu Y, Chen X, Wang D, Li H, Huang J, Zhang Z, et al. Hemofiltration Successfully Eliminates Severe Cytokine Release Syndrome Following CD19 CAR-T-Cell Therapy. J Immunother (2018) 41:406-10. doi: 10.1097/ cji.0000000000000243

111. Constantinescu C, Pasca S, Tat T, Teodorescu P, Vlad C, Iluta S, et al. Continuous Renal Replacement Therapy in Cytokine Release Syndrome Following Immunotherapy or Cellular Therapies? I Immunother Cancer (2020) 8:e000742. doi: 10.1136/jitc-2020-000742

112. Frey NV, Porter DL. Cytokine Release Syndrome With Novel Therapeutics for Acute Lymphoblastic Leukemia. Hematol Am Soc Hematol Educ Program (2016) 2016:567-72. doi: 10.1182/asheducation-2016.1.567

113. Frey NV, Shaw PA, Hexner EO, Pequignot E, Gill S, Luger SM, et al. Optimizing Chimeric Antigen Receptor T-Cell Therapy for Adults With Acute Lymphoblastic Leukemia. J Clin Oncol: Off J Am Soc Clin Oncol (2020) 38:415-22. doi: 10.1200/jco.19.01892

114. Frey NV, Shaw PA, Hexner EO, Gill S, Marcucci K, Luger SM, et al. Optimizing Chimeric Antigen Receptor (CAR) T Cell Therapy for Adult Patients With Relapsed or Refractory (R/R) Acute Lymphoblastic Leukemia (ALL). J Clin Oncol (2016) 34:7002. doi: 10.1200/JCO.2016.34.15_suppl.7002

115. Martínez Bedoya D, Dutoit V, Migliorini D. Allogeneic CAR T Cells: An Alternative to Overcome Challenges of CAR T Cell Therapy in Glioblastoma. Front Immunol (2021) 12:640082. doi: 10.3389/fimmu.2021.640082

116. Dudley ME, Yang JC, Sherry R, Hughes MS, Royal R, Kammula U, et al. Adoptive Cell Therapy for Patients With Metastatic Melanoma: Evaluation of Intensive Myeloablative Chemoradiation Preparative Regimens. J Clin Oncol (2008) 26:5233-9. doi: 10.1200/JCO.2008.16.5449

117. Muranski P, Boni A, Wrzesinski C, Citrin DE, Rosenberg SA, Childs R, et al. Increased Intensity Lymphodepletion and Adoptive Immunotherapy-How Far can We Go? Nat Clin Pract Oncol (2006) 3:668-81. doi: 10.1038/ ncponc0666

118. Gattinoni L, Finkelstein SE, Klebanoff CA, Antony PA, Palmer DC, Spiess PJ, et al. Removal of Homeostatic Cytokine Sinks by Lymphodepletion Enhances the Efficacy of Adoptively Transferred Tumor-Specific CD8+ T Cells. J Exp Med (2005) 202:907-12. doi: 10.1084/jem.20050732

119. Ninomiya S, Narala N, Huye L, Yagyu S, Savoldo B, Dotti G, et al. Tumor Indoleamine 2, 3-Dioxygenase (IDO) Inhibits CD19-CAR T Cells and is Downregulated by Lymphodepleting Drugs. Blood J Am Soc Hematol (2015) 125:3905-16. doi: 10.1182/blood-2015-01-621474

120. Turtle CJ, Hanafi L-A, Berger C, Hudecek M, Pender B, Robinson E, et al. Immunotherapy of non-Hodgkin's Lymphoma With a Defined Ratio of CD8 + and CD4+ CD19-Specific Chimeric Antigen Receptor-Modified T Cells. Sci Trans Med (2016) 8:355ra116-355ra116. doi: 10.1126/ scitranslmed.aaf 8621

121. Turtle CJ, Hanafi L-A, Berger C, Sommermeyer D, Pender B, Robinson EM, et al. Addition of Fludarabine to Cyclophosphamide Lymphodepletion Improves In Vivo Expansion of CD19 Chimeric Antigen Receptor-Modified T Cells and Clinical Outcome in Adults With B Cell Acute Lymphoblastic Leukemia. Blood (2015) 126:3773-. doi: 10.1182/blood.V126.23.3773.3773

122. Kochenderfer JN, Somerville RP, Lu T, Shi V, Bot A, Rossi J, et al. Lymphoma Remissions Caused by Anti-CD19 Chimeric Antigen Receptor 
T Cells are Associated With High Serum Interleukin-15 Levels. J Clin Oncol (2017) 35:1803. doi: 10.1200/JCO.2016.71.3024

123. Hirayama AV, Gauthier J, Hay KA, Voutsinas JM, Wu Q, Gooley T, et al. The Response to Lymphodepletion Impacts PFS in Patients With Aggressive non-Hodgkin Lymphoma Treated With CD19 CAR T Cells. Blood (2019) 133:1876-87. doi: 10.1182/blood-2018-11-887067

124. Ding BB, Gray JD, Krapf I, Zhang Y, Zhang N, Deng QM, et al. Development of a Genetically-Engineered Allogeneic Anti-CD38 T Cell Therapy Utilizing a Novel Antigen Receptor Structure. Blood (2019) 134:4444-. doi: 10.1182/ blood-2019-131586

125. Ding BB, Gray JD, Zhang N, Zhang Y, Cao X, Krapf I, et al. Development of an Allogeneic Anti-Bcma T Cell Therapy Utilizing a Novel Dimeric Antigen Receptor (DAR) Structure. Blood (2019) 134:1942-. doi: 10.1182/blood2019-131892

126. Kamali E, Rahbarizadeh F, Hojati Z, Frödin M. CRISPR/Cas9-Mediated Knockout of Clinically Relevant Alloantigenes in Human Primary T Cells. BMC Biotechnol (2021) 21:9. doi: 10.1186/s12896-020-00665-4

127. Kamali E, Hojati Z, Rahbarizadeh F. Targeted Gene Editing in Human Primary T Cells Using CRISPR/Cas9 Ribonucleoproteins. J Isfahan Med School (2021) 39:66-75. doi: 10.22122/jims.v39i1.13586

128. Torikai H, Reik A, Liu P-Q, Zhou Y, Zhang L, Maiti S, et al. A Foundation for Universal T-Cell Based Immunotherapy: T Cells Engineered to Express a CD19Specific Chimeric-Antigen-Receptor and Eliminate Expression of Endogenous TCR. Blood (2012) 119:5697-705. doi: 10.1182/blood-2012-01-405365

129. Torikai H, Reik A, Soldner F, Warren EH, Yuen C, Zhou Y, et al. Toward Eliminating HLA Class I Expression to Generate Universal Cells From Allogeneic Donors. Blood (2013) 122:1341-9. doi: 10.1182/blood-2013-03478255

130. Poirot L, Philip B, Schiffer-Mannioui C, Le Clerre D, Chion-Sotinel I, Derniame S, et al. Multiplex Genome-Edited T-Cell Manufacturing Platform for "Off-The-Shelf" Adoptive T-Cell Immunotherapies. Cancer Res (2015) 75:3853-64. doi: 10.1158/0008-5472.Can-14-3321

131. Valton J, Guyot V, Marechal A, Filhol JM, Juillerat A, Duclert A, et al. A Multidrug-Resistant Engineered CAR T Cell for Allogeneic Combination Immunotherapy. Mol Ther (2015) 23:1507-18. doi: 10.1038/mt.2015.104

132. Qasim W, Zhan H, Samarasinghe S, Adams S, Amrolia P, Stafford S, et al. Molecular Remission of Infant B-ALL After Infusion of Universal TALEN Gene-Edited CAR T Cells. Sci Transl Med (2017) 9:eaaj2013. doi: 10.1126/ scitranslmed.aaj2013

133. Benjamin R, Graham C, Yallop D, Jozwik A, Mirci-Danicar OC, Lucchini G, et al. Genome-Edited, Donor-Derived Allogeneic Anti-CD19 Chimeric Antigen Receptor T Cells in Paediatric and Adult B-Cell Acute Lymphoblastic Leukaemia: Results of Two Phase 1 Studies. Lancet (London England) (2020) 396:1885-94. doi: 10.1016/s0140-6736(20)32334-5

134. Eyquem J, Mansilla-Soto J, Giavridis T, van der Stegen SJ, Hamieh M, Cunanan KM, et al. Targeting a CAR to the TRAC Locus With CRISPR/Cas9 Enhances Tumour Rejection. Nature (2017) 543:113-7. doi: 10.1038/nature21405

135. Georgiadis C, Preece R, Nickolay L, Etuk A, Petrova A, Ladon D, et al. Long Terminal Repeat CRISPR-CAR-Coupled "Universal" T Cells Mediate Potent Anti-Leukemic Effects. Mol Ther (2018) 26:1215-27. doi: 10.1016/ j.ymthe.2018.02.025

136. MacLeod DT, Antony J, Martin AJ, Moser RJ, Hekele A, Wetzel KJ, et al. Integration of a CD19 CAR Into the TCR Alpha Chain Locus Streamlines Production of Allogeneic Gene-Edited CAR T Cells. Mol Ther (2017) 25:949-61. doi: 10.1016/j.ymthe.2017.02.005

137. Ren J, Zhang X, Liu X, Fang C, Jiang S, June CH, et al. A Versatile System for Rapid Multiplex Genome-Edited CAR T Cell Generation. Oncotarget (2017) 8:17002-11. doi: 10.18632/oncotarget.15218

138. Stenger D, Stief TA, Kaeuferle T, Willier S, Rataj F, Schober K, et al. Endogenous TCR Promotes In Vivo Persistence of CD19-CAR-T Cells Compared to a CRISPR/Cas9-Mediated TCR Knockout CAR. Blood (2020) 136:1407-18. doi: 10.1182/blood.2020005185

139. Nakazawa Y, Huye LE, Salsman VS, Leen AM, Ahmed N, Rollins L, et al. PiggyBac-Mediated Cancer Immunotherapy Using EBV-Specific Cytotoxic T-Cells Expressing HER2-Specific Chimeric Antigen Receptor. Mol Ther (2011) 19:2133-43. doi: 10.1038/mt.2011.131

140. Shen RR, Pham CD, Wu MM, Munson DJ, Aftab BT. Abstract 2310: Functional Demonstration of CD19 Chimeric Antigen Receptor (CAR)
Engineered Epstein-Barr Virus (EBV) Specific T Cells: An Off-the-Shelf, Allogeneic CAR T-Cell Immunotherapy Platform. Cancer Res (2019) 79:2310-. doi: 10.1158/1538-7445.Am2019-2310

141. Barrett AJ, Prockop S, Bollard CM. Virus-Specific T Cells: Broadening Applicability. Biol Blood Marrow Transplant (2018) 24:13-8. doi: 10.1016/ j.bbmt.2017.10.004

142. Cruz CR, Micklethwaite KP, Savoldo B, Ramos CA, Lam S, Ku S, et al. Infusion of Donor-Derived CD19-Redirected Virus-Specific T Cells for BCell Malignancies Relapsed After Allogeneic Stem Cell Transplant: A Phase 1 Study. Blood (2013) 122:2965-73. doi: 10.1182/blood-2013-06-506741

143. Ahmed N, Brawley V, Hegde M, Bielamowicz K, Kalra M, Landi D, et al. HER2-Specific Chimeric Antigen Receptor-Modified Virus-Specific T Cells for Progressive Glioblastoma: A Phase 1 Dose-Escalation Trial. JAMA Oncol (2017) 3:1094-101. doi: 10.1001/jamaoncol.2017.0184

144. Chang C, van der Stegen S, Mili M, Clarke R, Lai Y-S, Witty A, et al. FT819: Translation of Off-The-Shelf TCR-Less Trac-1xx CAR-T Cells in Support of First-Of-Kind Phase I Clinical Trial. Blood (2019) 134:4434. doi: 10.1182/ blood-2019-130584

145. Clarke R, van der Stegen S, Chang C-W, Husain M, Lai Y-S, Peralta E, et al. Pluripotent Cell-Derived Off-The-Shelf TCR-Less CAR-Targeted Cytotoxic $\mathrm{T}$ Cell Therapeutic for the Allogeneic Treatment of B Cell Malignancies. Blood (2018) 132:4546-. doi: 10.1182/blood-2018-99-116843

146. Karasiewicz K, He S, Ng M, Tess K, Ling W, Kaufmann GF, et al. Preclinical Evaluation of Human Placental-Derived Allogeneic CD19 CAR-T Cells Against B Cell Malignancies. Blood (2019) 134:3222-. doi: 10.1182/blood2019-130782

147. Elliott TJ, Eisen HN. Allorecognition of Purified Major Histocompatibility Complex Glycoproteins by Cytotoxic T Lymphocytes. Proc Natl Acad Sci USA (1988) 85:2728-32. doi: 10.1073/pnas.85.8.2728

148. Ciccone E, Pende D, Viale O, Di Donato C, Tripodi G, Orengo AM, et al. Evidence of a Natural Killer (NK) Cell Repertoire for (Allo) Antigen Recognition: Definition of Five Distinct NK-Determined Allospecificities in Humans. J Exp Med (1992) 175:709-18. doi: 10.1084/jem.175.3.709

149. Ruggeri L, Capanni M, Urbani E, Perruccio K, Shlomchik WD, Tosti A, et al. Effectiveness of Donor Natural Killer Cell Alloreactivity in Mismatched Hematopoietic Transplants. Science (2002) 295:2097-100. doi: 10.1126/ science. 1068440

150. Colonna M, Brooks EG, Falco M, Ferrara GB, Strominger JL. Generation of Allospecific Natural Killer Cells by Stimulation Across a Polymorphism of HLA-C. Science (1993) 260:1121-4. doi: 10.1126/science.8493555

151. Mo F, Watanabe N, McKenna MK, Hicks MJ, Srinivasan M, Gomes-Silva D, et al. Engineered Off-the-Shelf Therapeutic T Cells Resist Host Immune Rejection. Nat Biotechnol (2020) 39:56-63. doi: 10.1038/s41587-020-0601-5

152. Cai B, Guo M, Wang Y, Zhang Y, Yang J, Guo Y, et al. Co-Infusion of HaploIdentical CD19-Chimeric Antigen Receptor T Cells and Stem Cells Achieved Full Donor Engraftment in Refractory Acute Lymphoblastic Leukemia. J Hematol Oncol (2016) 9:131. doi: 10.1186/s13045-016-0357-z

153. Zhang C, Kong PY, Li S, Chen T, Ni X, Li Y, et al. Donor-Derived CAR-T Cells Serve as a Reduced-Intensity Conditioning Regimen for Haploidentical Stem Cell Transplantation in Treatment of Relapsed/Refractory Acute Lymphoblastic Leukemia: Case Report and Review of the Literature. J Immunother (2018) 41:306-11. doi: 10.1097/cji.0000000000000233

154. Zhang JP, Zhang R, Tsao ST, Liu YC, Chen X, Lu DP, et al. Sequential Allogeneic and Autologous CAR-T-Cell Therapy to Treat an ImmuneCompromised Leukemic Patient. Blood Adv (2018) 2:1691-5. doi: 10.1182/ bloodadvances.2018017004

155. Porter DL, Hwang WT, Frey NV, Lacey SF, Shaw PA, Loren AW, et al. Chimeric Antigen Receptor T Cells Persist and Induce Sustained Remissions in Relapsed Refractory Chronic Lymphocytic Leukemia. Sci Transl Med (2015) 7:303ra139. doi: 10.1126/scitranslmed.aac5415

156. Kochenderfer JN, Dudley ME, Feldman SA, Wilson WH, Spaner DE, Maric I, et al. B-Cell Depletion and Remissions of Malignancy Along With CytokineAssociated Toxicity in a Clinical Trial of Anti-CD19 Chimeric-AntigenReceptor-Transduced T Cells. Blood (2012) 119:2709-20. doi: 10.1182/blood2011-10-384388

157. Kochenderfer JN, Wilson WH, Janik JE, Dudley ME, Stetler-Stevenson M, Feldman SA, et al. Eradication of B-Lineage Cells and Regression of Lymphoma in a Patient Treated With Autologous T Cells Genetically 
Engineered to Recognize CD19. Blood (2010) 116:4099-102. doi: 10.1182/ blood-2010-04-281931

158. Perez EE, Orange JS, Bonilla F, Chinen J, Chinn IK, Dorsey M, et al. Update on the Use of Immunoglobulin in Human Disease: A Review of Evidence. J Allergy Clin Immunol (2017) 139:S1-s46. doi: 10.1016/j.jaci.2016.09.023

159. Berger M, Rojavin M, Kiessling P, Zenker O. Pharmacokinetics of Subcutaneous Immunoglobulin and Their Use in Dosing of Replacement Therapy in Patients With Primary Immunodeficiencies. Clin Immunol (2011) 139:133-41. doi: 10.1016/j.clim.2011.01.006

160. Berger M, Murphy E, Riley P, Bergman GE. Improved Quality of Life, Immunoglobulin G Levels, and Infection Rates in Patients With Primary Immunodeficiency Diseases During Self-Treatment With Subcutaneous Immunoglobulin G. South Med J (2010) 103:856-63. doi: 10.1097/ SMJ.0b013e3181eba6ea

161. Mallick R, Jolles S, Kanegane H, Agbor-Tarh D, Rojavin M. Treatment Satisfaction With Subcutaneous Immunoglobulin Replacement Therapy in Patients With Primary Immunodeficiency: A Pooled Analysis of Six Hizentra ${ }^{\circledR}$ Studies. J Clin Immunol (2018) 38:886-97. doi: 10.1007/s10875018-0562-3

162. Fu LW, Song C, Isaranuwatchai W, Betschel S. Home-Based Subcutaneous Immunoglobulin Therapy vs Hospital-Based Intravenous Immunoglobulin Therapy: A Prospective Economic Analysis. Ann Allergy Asthma Immunol (2018) 120:195-9. doi: 10.1016/j.anai.2017.11.002

163. Windegger TM, Nghiem S, Nguyen KH, Fung YL, Scuffham PA. CostUtility Analysis Comparing Hospital-Based Intravenous Immunoglobulin With Home-Based Subcutaneous Immunoglobulin in Patients With Secondary Immunodeficiency. Vox Sang (2019) 114:237-46. doi: $10.1111 /$ vox.12760

164. Hill JA, Li D, Hay KA, Green ML, Cherian S, Chen X, et al. Infectious Complications of CD19-Targeted Chimeric Antigen Receptor-Modified TCell Immunotherapy. Blood (2018) 131:121-30. doi: 10.1182/blood-2017-07793760

165. Kansagra AJ, Frey NV, Bar M, Laetsch TW, Carpenter PA, Savani BN, et al. Clinical Utilization of Chimeric Antigen Receptor T Cells in B Cell Acute Lymphoblastic Leukemia: An Expert Opinion From the European Society for Blood and Marrow Transplantation and the American Society for Transplantation and Cellular Therapy. Biol Blood Marrow Transplant (2019) 25:e76-85. doi: 10.1016/j.bbmt.2018.12.068

166. Hensley MK, Bain WG, Jacobs J, Nambulli S, Parikh U, Cillo A, et al. Intractable Coronavirus Disease 2019 (COVID-19) and Prolonged Severe Acute Respiratory Syndrome Coronavirus 2 (SARS-CoV-2) Replication in a Chimeric Antigen Receptor-Modified T-Cell Therapy Recipient: A Case Study. Clin Infect Dis: an Off Publ Infect Dis Soc Am (2021) 73:e815-21. doi: 10.1093/cid/ciab072

167. Ruella M, Xu J, Barrett DM, Fraietta JA, Reich TJ, Ambrose DE, et al. Induction of Resistance to Chimeric Antigen Receptor T Cell Therapy by Transduction of a Single Leukemic B Cell. Nat Med (2018) 24:1499-503. doi: 10.1038/s41591-018-0201-9

168. Ruella M, Barrett DM, Shestova O, Perazzelli J, Posey AD, Hong SJ, et al. A Cellular Antidote to Specifically Deplete Anti-CD19 Chimeric Antigen Receptor-Positive Cells. Blood (2020) 135:505-9. doi: 10.1182/ blood.2019001859

169. Jena B, Maiti S, Huls H, Singh H, Lee DA, Champlin RE, et al. Chimeric Antigen Receptor (CAR)-Specific Monoclonal Antibody to Detect CD19Specific T Cells in Clinical Trials. PloS One (2013) 8:e57838. doi: 10.1371/ journal.pone.0057838

170. Paszkiewicz PJ, Fräßle SP, Srivastava S, Sommermeyer D, Hudecek M, Drexler I, et al. Targeted Antibody-Mediated Depletion of Murine CD19 CAR T Cells Permanently Reverses B Cell Aplasia. J Clin Invest (2016) 126:4262-72. doi: $10.1172 /$ jci84813

171. Riddell SR, Sommermeyer D, Berger C, Liu LS, Balakrishnan A, Salter A, et al. Adoptive Therapy With Chimeric Antigen Receptor Modified T Cells of Defined Subset Composition. Cancer J (Sudbury Mass) (2014) 20:141. doi: 10.1097/PPO.0000000000000036

172. Berger C, Jensen MC, Lansdorp PM, Gough M, Elliott C, Riddell SR. Adoptive Transfer of Effector CD8+ T Cells Derived From Central Memory Cells Establishes Persistent T Cell Memory in Primates. J Clin Invest (2008) 118:294-305. doi: 10.1172/JCI32103
173. Gattinoni L, Lugli E, Ji Y, Pos Z, Paulos CM, Quigley MF, et al. A Human Memory T Cell Subset With Stem Cell-Like Properties. Nat Med (2011) 17:1290. doi: $10.1038 / \mathrm{nm} .2446$

174. Stemberger C, Neuenhahn M, Gebhardt FE, Schiemann M, Buchholz VR, Busch DH. Stem Cell-Like Plasticity of Naïve and Distinct Memory CD8+ T Cell Subsets. Semin Immunol (2009) 21:62-8. doi: 10.1016/j.smim. 2009.02.004

175. Turtle CJ, Delrow J, Joslyn RC, Swanson HM, Basom R, Tabellini L, et al. Innate Signals Overcome Acquired TCR Signaling Pathway Regulation and Govern the Fate of Human CD161hi Cd8 $\alpha+$ Semi-Invariant T Cells. Blood J Am Soc Hematol (2011) 118:2752-62. doi: 10.1182/blood-2011-02-334698

176. Wang X, Berger C, Wong CW, Forman SJ, Riddell SR, Jensen MC. Engraftment of Human Central Memory-Derived Effector CD8+ T Cells in Immunodeficient Mice. Blood J Am Soc Hematol (2011) 117:1888-98. doi: 10.1182/blood-2010-10-310599

177. Shah NN, Highfill SL, Shalabi H, Yates B, Jin J, Wolters PL, et al. CD4/CD8 T-Cell Selection Affects Chimeric Antigen Receptor (CAR) T-Cell Potency and Toxicity: Updated Results From a Phase I Anti-CD22 CAR T-Cell Trial. J Clin Oncol (2020) 38:1938-50. doi: 10.1200/JCO.19.03279

178. Sommermeyer D, Hudecek M, Kosasih PL, Gogishvili T, Maloney DG, Turtle CJ, et al. Chimeric Antigen Receptor-Modified T Cells Derived From Defined CD8+ and CD4+ Subsets Confer Superior Antitumor Reactivity In Vivo. Leukemia (2016) 30:492-500. doi: 10.1038/leu.2015.247

179. Graef P, Buchholz VR, Stemberger C, Flossdorf M, Henkel L, Schiemann M, et al. Serial Transfer of Single-Cell-Derived Immunocompetence Reveals Stemness of CD8+ Central Memory T Cells. Immunity (2014) 41:116-26. doi: 10.1016/j.immuni.2014.05.018

180. Turtle CJ, Hanafi L-A, Berger C, Gooley TA, Cherian S, Hudecek M, et al. CD19 CAR-T Cells of Defined CD4+: CD8+ Composition in Adult B Cell ALL Patients. J Clin Invest (2016) 126:2123-38. doi: 10.1172/JCI85309

181. Biasco L, Izotova N, Rivat C, Ghorashian S, Richardson R, Guvenel A, et al. Clonal Expansion of T Memory Stem Cells Determines Early Anti-Leukemic Responses and Long-Term CAR T Cell Persistence in Patients. Nat Cancer (2021) 2:629-42. doi: 10.1038/s43018-021-00207-7

182. Brudno JN, Kochenderfer JN. Recent Advances in CAR T-Cell Toxicity: Mechanisms, Manifestations and Management. Blood Rev (2019) 34:45-55. doi: 10.1016/j.blre.2018.11.002

183. Ghassemi S, Martinez-Becerra F, Master A, Richman S, Heo D, Leferovich J, et al. Novel Media Formulations to Enhance Chimeric Antigen Receptor (CAR) T-Cell Potency and Anti-Tumor Cell Function for Adoptive Immunotherapy. Cytotherapy (2020) 22:S133. doi: 10.1016/j.jcyt.2020.03.260

184. Ghassemi S, Martinez-Becerra FJ, Master AM, Richman SA, Heo D, Leferovich J, et al. Enhancing Chimeric Antigen Receptor T Cell AntiTumor Function Through Advanced Media Design. Mol Ther Methods Clin Dev (2020) 18:595-606. doi: 10.1016/j.omtm.2020.07.008

185. Geiger R, Rieckmann JC, Wolf T, Basso C, Feng Y, Fuhrer T, et al. L-Arginine Modulates T Cell Metabolism and Enhances Survival and Anti-Tumor Activity. Cell (2016) 167:829-42.e13. doi: 10.1016/j.cell.2016.09.031

186. Li Y, Kurlander RJ. Comparison of Anti-CD3 and Anti-CD28-Coated Beads With Soluble Anti-CD3 for Expanding Human T Cells: Differing Impact on CD8 T Cell Phenotype and Responsiveness to Restimulation. J Trans Med (2010) 8:104. doi: 10.1186/1479-5876-8-104

187. Xu Y, Zhang M, Ramos CA, Durett A, Liu E, Dakhova O, et al. Closely Related T-Memory Stem Cells Correlate With In Vivo Expansion of CAR.CD19-T Cells and are Preserved by IL-7 and IL-15. Blood (2014) 123:3750-9. doi: 10.1182/blood-2014-01-552174

188. Giuffrida L, Sek K, Henderson MA, House IG, Lai J, Chen AXY, et al. IL-15 Preconditioning Augments CAR T Cell Responses to Checkpoint Blockade for Improved Treatment of Solid Tumors. Mol Ther (2020) 28:2379-93. doi: 10.1016/j.ymthe.2020.07.018

189. Alizadeh D, Wong RA, Yang X, Wang D, Pecoraro JR, Kuo CF, et al. IL15 Enhances CAR-T Cell Antitumor Activity by Reducing Mtorcl Activity and Preserving Their Stem Cell Memory Phenotype. Cancer Immunol Res (2019) 7:759-72. doi: 10.1158/2326-6066.Cir-18-0466

190. Canestrari E, Steidinger HR, McSwain B, Charlebois SJ, Dann CT. Human Platelet Lysate Media Supplement Supports Lentiviral Transduction and Expansion of Human T Lymphocytes While Maintaining Memory Phenotype. J Immunol Res (2019) 2019:3616120. doi: 10.1155/2019/3616120 
191. Torres Chavez A, McKenna MK, Canestrari E, Dann CT, Ramos CA, Lulla P, et al. Expanding CAR T Cells in Human Platelet Lysate Renders T Cells With. Vivo Longev J Immunother Cancer (2019) 7:330. doi: 10.1186/s40425019-0804-9

192. Tyrakis PA, Palazon A, Macias D, Lee KL, Phan AT, Veliça P, et al. S-2Hydroxyglutarate Regulates CD8(+) T-Lymphocyte Fate. Nature (2016) 540:236-41. doi: 10.1038/nature20165

193. Foskolou IP, Barbieri L, Vernet A, Bargiela D, Cunha PP, Velica P, et al. The $S$ Enantiomer of 2-Hydroxyglutarate Increases Central Memory CD8 Populations and Improves CAR-T Therapy Outcome. Blood Adv (2020) 4:4483-93. doi: 10.1182/bloodadvances.2020002309

194. Ghassemi S, Nunez-Cruz S, O’Connor RS, Fraietta JA, Patel PR, Scholler J, et al. Reducing Ex Vivo Culture Improves the Antileukemic Activity of Chimeric Antigen Receptor (CAR) T Cells. Cancer Immunol Res (2018) 6:1100-9. doi: 10.1158/2326-6066.Cir-17-0405

195. Sukumar M, Liu J, Ji Y, Subramanian M, Crompton JG, Yu Z, et al. Inhibiting Glycolytic Metabolism Enhances CD8+ T Cell Memory and Antitumor Function. J Clin Invest (2013) 123:4479-88. doi: 10.1172/jci69589

196. Crompton JG, Sukumar M, Roychoudhuri R, Clever D, Gros A, Eil RL, et al. Akt Inhibition Enhances Expansion of Potent Tumor-Specific Lymphocytes With Memory Cell Characteristics. Cancer Res (2015) 75:296-305. doi: 10.1158/0008-5472.Can-14-2277

197. Urak R, Walter M, Lim L, Wong CW, Budde LE, Thomas S, et al. Ex Vivo Akt Inhibition Promotes the Generation of Potent CD19CAR T Cells for Adoptive Immunotherapy. J Immunother Cancer (2017) 5:26. doi: 10.1186/ s40425-017-0227-4

198. Carty SA, Gohil M, Banks LB, Cotton RM, Johnson ME, Stelekati E, et al. The Loss of TET2 Promotes CD8(+) T Cell Memory Differentiation. J Immunol (2018) 200:82-91. doi: 10.4049/jimmunol.1700559

199. Fraietta JA, Nobles CL, Sammons MA, Lundh S, Carty SA, Reich TJ, et al. Disruption of TET2 Promotes the Therapeutic Efficacy of CD19-Targeted T Cells. Nature (2018) 558:307-12. doi: 10.1038/s41586-018-0178-z

200. Kondo T, Morita R, Okuzono Y, Nakatsukasa H, Sekiya T, Chikuma S, et al. Notch-Mediated Conversion of Activated T Cells Into Stem Cell MemoryLike T Cells for Adoptive Immunotherapy. Nat Commun (2017) 8:15338. doi: $10.1038 /$ ncomms 15338
201. Kondo T, Imura Y, Chikuma S, Hibino S, Omata-Mise S, Ando M, et al. Generation and Application of Human Induced-Stem Cell Memory T Cells for Adoptive Immunotherapy. Cancer Sci (2018) 109:2130-40. doi: 10.1111/ cas. 13648

202. Kondo T, Imura Y, Ando M, Chikuma S, Yoshimura A. In Vitro Conversion of Activated T Cells Into Stem Cell Memory-Like T Cells. Methods Mol Biol (2019) 2048:41-51. doi: 10.1007/978-1-4939-9728-2_4

203. Kondo T, Ando M, Nagai N, Tomisato W, Srirat T, Liu B, et al. The NOTCH-FOXM1 Axis Plays a Key Role in Mitochondrial Biogenesis in the Induction of Human Stem Cell Memory-Like CAR-T Cells. Cancer Res (2020) 80:471-83. doi: 10.1158/0008-5472.Can-19-1196

204. Kawalekar OU, O'Connor RS, Fraietta JA, Guo L, McGettigan SE, Posey AD Jr, et al. Distinct Signaling of Coreceptors Regulates Specific Metabolism Pathways and Impacts Memory Development in CAR T Cells. Immunity (2016) 44:380-90. doi: 10.1016/j.immuni.2016.01.021

205. DiNofia AM, Grupp SA. Will Allogeneic CAR T Cells for CD19(+) Malignancies Take Autologous CAR T Cells 'Off the Shelf? Nat Rev Clin Oncol (2021) 18:195-6. doi: 10.1038/s41571-021-00485-1

Conflict of Interest: The authors declare that the research was conducted in the absence of any commercial or financial relationships that could be construed as a potential conflict of interest.

Publisher's Note: All claims expressed in this article are solely those of the authors and do not necessarily represent those of their affiliated organizations, or those of the publisher, the editors and the reviewers. Any product that may be evaluated in this article, or claim that may be made by its manufacturer, is not guaranteed or endorsed by the publisher.

Copyright (๑) 2021 Safarzadeh Kozani, Safarzadeh Kozani and Rahbarizadeh. This is an open-access article distributed under the terms of the Creative Commons Attribution License (CC BY). The use, distribution or reproduction in other forums is permitted, provided the original author $(s)$ and the copyright owner(s) are credited and that the original publication in this journal is cited, in accordance with accepted academic practice. No use, distribution or reproduction is permitted which does not comply with these terms. 